\title{
Lateralization (handedness) in Magellanic penguins
}

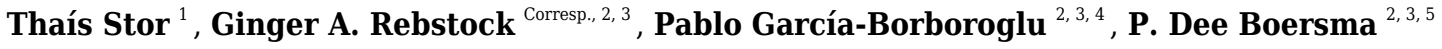 \\ ${ }^{1}$ Centro de Ciências Biológicas, Departamento de Ornitologia, Universidade Federal de Pernambuco, Recife, Pernambuco, Brazil \\ 2 Center for Ecosystem Sentinels, Department of Biology, University of Washington, Seattle, Washington, United States \\ 3 Global Penguin Society, Puerto Madryn, Chubut, Argentina \\ 4 CESIMAR, CCT - CENPAT - CONICET, Puerto Madryn, Chubut, Argentina \\ 5 Wildlife Conservation Society, Bronx, New York, United States \\ Corresponding Author: Ginger A. Rebstock \\ Email address: gar@uw.edu
}

Lateralization, or asymmetry in form and/or function, is found in many animal species. Brain lateralization is considered adaptive for an individual, and often results in "handedness", "footedness", or a side preference, manifest in behavior and morphology. We tested for lateralization in several behaviors in a wild population of Magellanic penguins Spheniscus magellanicus breeding at Punta Tombo, Argentina. We found no preferred foot in the population (each penguin observed once) in stepping up onto an obstacle: $53 \%$ stepped up with the right foot, $47 \%$ with the left foot $(n=300$, binomial test $p=0.27)$. We found mixed evidence for a dominant foot when a penguin extended a foot for thermoregulation, possibly depending on the ambient temperature (each penguin observed once). Penguins extended the right foot twice as often as the left foot ( $n=121, p$ $<0.0005$ ) in two years when we concentrated our effort during the heat of the day. In a third year when we observed penguins early and late in the day, there was no preference ( $n=232, p=0.59$ ). Penguins use their flippers for swimming, including searching for and chasing prey. We found morphological evidence of a dominant flipper in individual adults: $60.5 \%$ of sternum keels curved one direction or the other ( $n=76$ sterna from carcasses), and $11 \%$ of penguins had more feather wear on one flipper than the other $(n=1217)$. Right-flippered and left-flippered penguins were equally likely in both samples (keels: $p=$ 0.88 , feather wear: $p=0.26$ ), indicating individual but not population lateralization. In fights, aggressive penguins used their left eyes preferentially, consistent with the right side of the brain controlling aggression. Penguins that recently fought (each penguin observed once) were twice as likely to have blood only on the right side of the face $(69 \%)$ as only on the left side $(31 \%, n=175, p<0.001)$. The proportion of penguins with blood only on the right side increased with the amount of blood. In most fights, the more aggressive penguin used its left eye and attacked the other penguin's right side. 
Lateralization depended on the behavior tested and, in thermoregulation, likely on the temperature. We found no lateralization or mixed results in the population of Magellanic penguins in three individual behaviors, stepping up, swimming, and thermoregulation. We found lateralization in the population in the social behavior fighting. 


\section{Lateralization (handedness) in Magellanic penguins}

3

4 Thaís Stor ${ }^{1}$, Ginger A. Rebstock ${ }^{2,3}$, Pablo García-Borboroglu ${ }^{2,3,4}$, P. Dee Boersma ${ }^{2,3,5}$

5

$6{ }^{1}$ Centro de Ciências Biológicas, Departamento de Ornitologia, Universidade Federal de

7 Pernambuco, Recife, Brazil

$8{ }^{2}$ Center for Ecosystem Sentinels, Department of Biology, University of Washington, Seattle, 9 WA, USA

$10{ }^{3}$ Global Penguin Society, Puerto Madryn, Chubut, Argentina

$11{ }^{4}$ CESIMAR, CCT - CENPAT - CONICET, Puerto Madryn, Chubut, Argentina

$12{ }^{5}$ Wildlife Conservation Society, Bronx, New York, USA

13

14 Corresponding author:

15 Ginger A. Rebstock ${ }^{2}$

16 Box 351800, University of Washington, Seattle, WA 98195-1800 USA

17 Email address: gar@uw.edu

18

19 
20

21

22

\section{ABSTRACT}

Lateralization, or asymmetry in form and/or function, is found in many animal species.

Brain lateralization is considered adaptive for an individual, and often results in "handedness", "footedness", or a side preference, manifest in behavior and morphology. We tested for lateralization in several behaviors in a wild population of Magellanic penguins Spheniscus magellanicus breeding at Punta Tombo, Argentina. We found no preferred foot in the population (each penguin observed once) in stepping up onto an obstacle: 53\% stepped up with the right foot, $47 \%$ with the left foot $(n=300$, binomial test $p=0.27)$. We found mixed evidence for a dominant foot when a penguin extended a foot for thermoregulation, possibly depending on the ambient temperature (each penguin observed once). Penguins extended the right foot twice as often as the left foot $(\mathrm{n}=121, \mathrm{p}<0.0005)$ in two years when we concentrated our effort during the heat of the day. In a third year when we observed penguins early and late in the day, there was no preference $(n=232, p=0.59)$. Penguins use their flippers for swimming, including searching for and chasing prey. We found morphological evidence of a dominant flipper in individual adults: $60.5 \%$ of sternum keels curved one direction or the other $(\mathrm{n}=76$ sterna from carcasses), and $11 \%$ of penguins had more feather wear on one flipper than the other $(n=1217)$. Right-flippered and left-flippered penguins were equally likely in both samples (keels: $\mathrm{p}=0.88$, feather wear: $p=0.26$ ), indicating individual but not population lateralization. In fights, aggressive penguins used their left eyes preferentially, consistent with the right side of the brain controlling aggression. Penguins that recently fought (each penguin observed once) were twice as likely to have blood only on the right side of the face $(69 \%)$ as only on the left side $(31 \%, \mathrm{n}=$ $175, \mathrm{p}<0.001)$. The proportion of penguins with blood only on the right side increased with the amount of blood. In most fights, the more aggressive penguin used its left eye and attacked the 
43 other penguin's right side. Lateralization depended on the behavior tested and, in

44 thermoregulation, likely on the temperature. We found no lateralization or mixed results in the

45 population of Magellanic penguins in three individual behaviors, stepping up, swimming, and

46 thermoregulation. We found lateralization in the population in the social behavior fighting.

47 


\section{INTRODUCTION}

49

50

51

52

Asymmetry in form and/or function, known as lateralization, is common in bilaterally symmetrical animals, including fish, amphibians, reptiles, birds, mammals, and a growing list of invertebrates (Bisazza, Rogers \& Vallortigara 1998; Frasnelli, Vallortigara \& Rogers 2012; Rogers 2017; Vallortigara, Chiandetti \& Sovrano 2011). Brain lateralization is hypothesized to be adaptive, especially in social or group behaviors (Bisazza et al. 2000; Bisazza, Rogers \& Vallortigara 1998; Ghirlanda, Frasnelli \& Vallortigara 2009; Ghirlanda \& Vallortigara 2004; Rogers 2017). Brain lateralization appears to enhance cognitive ability in an individual by allowing both brain hemispheres to specialize and function simultaneously (Rogers 2017), with less neural tissue (Ghirlanda \& Vallortigara 2004). It may also shorten reaction times (Dadda, Koolhaas \& Domenici 2010) and prevent conflicting responses from the two hemispheres when the eyes are not seeing the same scene (Ghirlanda \& Vallortigara 2004). Brain lateralization is often linked to behavioral lateralization, or to hand, foot, or paw preferences (Rogers 2009). The strength of lateralization may be more adaptive than its direction within an individual. In some species, lateralized individuals forage more efficiently, escape more rapidly, or make fewer motor errors regardless of the direction of lateralization (Bell \& Niven 2016; Dadda, Koolhaas \& Domenici 2010; Ghirlanda \& Vallortigara 2004; Kurvers et al. 2017). In addition, strength of lateralization can be inherited independently of direction (Bisazza, Rogers \& Vallortigara 1998). We tested for lateralization in a wild population of Magellanic penguins Spheniscus magellanicus (Forster, 1781) at a breeding colony in Argentina.

68 Brain lateralization is remarkably consistent among a wide range of taxa (Ghirlanda \& Vallortigara 2004; Rogers 2017; Vallortigara \& Rogers 2005). For example, the left hemisphere (which receives information from the right eye) controls approach and feeding behaviors 
71 including prey discrimination, capture, and manipulation, whereas the right hemisphere controls

72 avoidance behaviors, fear, and predator detection and escape behaviors (Vallortigara \& Rogers

73 2005). Aggression and intense emotions are inhibited by the left hemisphere and promoted by

74 the right (Bisazza, Rogers \& Vallortigara 1998). The left hemisphere functions in recognition of

75 broad categories and local landmarks and cues, and moderates or even delays responses (Rogers

76 2008). The right hemisphere functions in individual recognition and spatial cognition, and rapid

77 responses that are typical of the species (Rogers 2008).

Lateralization can occur within the population or within individuals. When more than

$50 \%$ of the individuals in a population are lateralized in the same direction it is referred to as

"population-level lateralization" (Bisazza, Rogers \& Vallortigara 1998), "handedness"

81 (Vallortigara 2015), or "directional asymmetry" (Vallortigara \& Rogers 2005). When at least

some individuals in the population are lateralized, but with equal numbers in each direction, it is referred to as "individual-level lateralization" (Bisazza, Rogers \& Vallortigara 1998), "hand preference" (Vallortigara 2015), or "antisymmetry" (Vallortigara \& Rogers 2005). Individual lateralization can occur without lateralization of the population. The brains of most animals

86 studied show some lateralization in individuals (Rogers 2017), but not all populations show a consistent hand, foot, paw, or side preference (Rogers 2009; Vallortigara 2015). Testing for lateralization within individuals requires multiple observations for each individual; testing for lateralization in the population requires one observation for each individual in a sample of the population.

Side preferences, manifested by behavior and morphology, are common even in animals

92 without hands or paws, such as marine mammals (MacNeilage 2014) and fish (Bisazza et al.

93 2000). Marine mammal populations often show strong lateralization in natural feeding behaviors, 
94 such as lunge feeding and beaching while herding fish, usually biased towards the right side. In

95 addition, right flipper bones are larger than left flipper bones in some dolphins and porpoises

96 (MacNeilage 2014). Individuals in many species of fish, especially schooling fish, preferentially

97 turn the same direction, which may function to coordinate movements in a school (Bisazza et al.

98 2000; Domenici 2010).

99 Side preferences in individuals (individual lateralization) depend on a variety of factors, 100 including the task or the behavioral context, age, physiological condition, and environmental

101 factors (Versace \& Vallortigara 2015). In humans, Huurnink and colleagues (2014) concluded 102 that "there is no such thing" as a dominant leg because the preferred leg depended on the task.

103 Human volunteers used the same leg more often in skilled than in unskilled tasks and foot 104 preference in humans can change during childhood (Schneiders et al. 2010). Lateralization 105 likewise changes with age in some birds and rodents (Bisazza, Rogers \& Vallortigara 1998). In 106 dogs, the preferred paw depended on the task, but was stable over six months within individuals 107 (Wells et al. 2018). The preferred foot used by budgerigars Melopsittacus undulatus also varied 108 with the task (Schiffner \& Srinivasan 2013). Herring Clupea harengus in a school had more 109 uniform escape directions than solitary individuals (Domenici 2010). In other fish species, 110 environmental factors such as oxygen levels, water temperature, and acclimation temperature 111 affected the directionality of escape responses (Domenici 2010).

112 Population lateralization also depends on the context, especially whether the behavior is 113 individual or social (Ghirlanda, Frasnelli \& Vallortigara 2009; Ghirlanda \& Vallortigara 2004). 114 Schooling fish and social insects are more likely to show population lateralization than solitary 115 fish and insects (Bisazza et al. 2000; Frasnelli, Vallortigara \& Rogers 2012). Even within a 
116 species, population lateralization is more likely in social behaviors than in individual behaviors

117 (Domenici 2010; Rogers, Frasnelli \& Versace 2016).

118 More observations of natural behaviors in wild populations are needed to confirm the

119 prevalence of lateralization found in laboratory studies. In particular, more studies of the same

120 species in a variety of behavioral contexts will provide a more complete understanding of

121 lateralization (Versace \& Vallortigara 2015). Penguins are easily observed in breeding colonies,

122 alone and interacting with other penguins. We looked for lateralization of individuals and

123 whether the lateralization was apparent for the population of Magellanic penguins at Punta

124 Tombo, Argentina. We examined behaviors in a variety of contexts: stepping up while walking

125 (individual behavior), extending a foot for thermoregulation (individual behavior), swimming

126 (individual behavior), and fighting (social behavior).

127 Dominant foot

128 We directly observed behavior on land to detect a dominant foot when a penguin stepped 129 up and when a penguin was prone in a thermoregulatory posture with a foot extended. We used

130 two tests because the dominant limb often depends on the task (Huurnink et al. 2014; Wells et al.

131 2018).

Individuals may use a dominant foot preferentially in stepping up onto an obstacle

133 (Huurnink et al. 2014; Tomkins, Thomson \& McGreevy 2010). Penguins do not balance on one

134 leg as some waterbirds do (Randler 2007), but walk between their nests and the beach many

135 times in a breeding season. They step over or onto obstacles that they encounter along the way.

136 Birds may use a dominant foot to step up or may use the dominant foot for balance and step up

137 with the other foot (Harris 1989; Tommasi \& Vallortigara 1999). We had no a priori reason to

138 hypothesize a particular dominant foot in the population of Magellanic penguins. 
extend one or occasionally both legs and feet for thermoregulation, particularly on hot days.

141 Thermoregulatory postures involve trade-offs with predation risks (Anderson \& Williams 2010;

142 Carr \& Lima 2012). Large mammals such as foxes (Lycalopex culpaeus), pumas (Puma

143 concolor), smaller wild cats (Leopardus spp.), and elephant seals (Mirounga leonina) prey on

144 adult penguins in continental colonies in South America (Clark \& Boersma 2006; Frere et al.

145 2010; Zanón Martínez et al. 2012), including Punta Tombo (Boersma, personal observation).

146 Penguins may have to get up quickly from a prone position when threatened by a predator or

147 another penguin. Thermoregulation may be a more likely behavior to show a dominant foot than

148 stepping up, as rising from a prone position likely requires more postural control (Tommasi \&

149 Vallortigara 1999) than stepping up.

150 In addition, penguins may have more blood flow to one leg than to the other as in pigeons

151 (Bernstein 1974). It would be more efficient to extend the leg and foot with more blood flow in

152 thermoregulation. The reproductive organs are on or more developed on the left side than the

153 right side in birds, which may result in more blood flow to the right side (Sturkie 1986). Gonads

154 require a large amount of blood (Sturkie 1986) and asymmetry in gonads may affect blood flow

155 to the feet. In most species of birds, including Magellanic penguins, females have a single ovary

156 and oviduct, on the left (Gill 1995). In males of many species, the left testis is larger than the

157 right (Birkhead, Fletcher \& Pellatt 1998). We hypothesized that penguins would extend the right

158 leg and foot preferentially for thermoregulation on hot days.

\section{Dominant flipper}

160 Penguins use their flippers for swimming and may have a dominant flipper because of the

161 lack of support water provides for sudden turns (reaction forces) (MacNeilage 2014). Schooling 
162 fish, the main prey of penguins (Frere, Gandini \& Lichtschein 1996; Wilson et al. 2005), tend to

163 turn one direction more than the other (Bisazza et al. 2000; Domenici 2010). Penguins are

164 opportunistic foragers, eating many species (Boersma et al. 2013; Frere, Gandini \& Lichtschein

165 1996), and the optimal dominant flipper for penguins may depend on the prey species if one

166 species tends to escape in one direction and another species escapes in the other direction.

167 Penguins often forage in groups, although they also forage alone (Berlincourt \& Arnould 2014;

168 Gómez-Laich, Yoda \& Quintana 2018; Jehl 1974; McInnes et al. 2017; Sutton, Hoskins \&

169 Arnould 2015; Wilson \& Wilson 1990). We expected lateralization of individuals but not in the 170 population.

A dominant flipper may result in structural asymmetries in the skeleton (MacNeilage

172 2014; Shaw \& Stock 2009) and in asymmetrical stresses on the feathers leading to excessive

173 feather wear on one flipper (Fallow et al. 2009). We assumed that the curved keels (carina) on

174 the sterna that we observed on penguin carcasses indicated a dominant flipper, as bones respond 175 over time to mechanical forces (Currey 2003). Known juvenile carcasses were rare. Juveniles 176 spend less time in the colony than adults do, as Magellanic penguins first breed at four years of 177 age or older (Boersma et al. 2013; Boersma, Stokes \& Yorio 1990).

Preferred fight orientation

Penguins fight during the breeding season (Renison, Boersma \& Martella 2002; Renison, Boersma \& Martella 2003; Renison et al. 2006) and may show evidence of lateralized brains in their preferred fighting orientation. The right hemisphere dominates in aggression (Bisazza, Rogers \& Vallortigara 1998) and many animals use their left eyes preferentially in aggressive interactions (Hews \& Worthington 2001; Rogers 2008). Because fighting is a social behavior it may be more likely than individual behaviors to show lateralization in the population (Bisazza et 
185

186

187

188

189

190

191

192

193

194

195

196

197

198

199

200

201

202

203

204

205

206

al. 2000; Ghirlanda \& Vallortigara 2004; Rogers, Frasnelli \& Versace 2016). We expected penguins to use their left eyes more often than their right eyes in fights.

We looked for evidence of brain lateralization in aggressive behavior by observing the distribution of blood on penguins' faces following fights, because it is difficult to directly observe a side preference in fights. Fights are uncommon, last only 2 or 3 minutes on average, often occur inside nests (Renison et al. 2006), and are difficult to observe or film from the beginning. Magellanic penguins, both males and females, fight over nests and frequently suffer cuts to the bare skin of the face (Renison, Boersma \& Martella 2002; Renison, Boersma \& Martella 2003; Renison et al. 2006), which might show lateralization.

We tested whether penguins display behavioral asymmetries in limb and eye use, mostly in the population, but in one case within individuals. We predicted that (1) equal numbers of penguins would step up onto an obstacle with the right and left legs (no lateralization of the population), but (2) more penguins would extend their right legs than their left legs during thermoregulation because of circulatory asymmetries (lateralization of the population). We further predicted that (3) individual penguins would have a dominant flipper, resulting in morphological asymmetries, but left- and right-flippered penguins would be equally likely in the population (individual, but not population lateralization). Finally, we predicted that (4) penguins would use their right hemispheres and left eyes in aggressive interactions, and would be bloodier on the left side than on the right side following fights (population lateralization).

\section{MATERIALS \& METHODS}

Study site and species 

2014), at least $1000 \mathrm{~km}$ north of Punta Tombo. Foraging trip distance during breeding depends on the stage of the breeding season, and ranges from a few kilometers to $>600 \mathrm{~km}$ (Boersma \& Rebstock 2009). Magellanic penguins feed in the ocean, usually on small schooling fish and squid, and sometimes crustaceans and jellyfish (Frere, Gandini \& Lichtschein 1996; Thiebot et al. 2017; Wilson et al. 2005). They often feed in small groups and in association with other seabirds and marine mammals (Gómez-Laich, Yoda \& Quintana 2018; Jehl 1974; Wilson \& Wilson 1990), and use their bills for prey capture and handling. heat stress (Boersma 1975; Boersma \& Rebstock 2014; Frost, Siegfried \& Burger 1976). Magellanic penguins nest primarily in burrows or under bushes, where they are protected from the sun (Rebstock, Boersma \& García-Borboroglu 2016; Stokes \& Boersma 1991). While breeding, they spend time on land, resting, incubating eggs, and brooding or guarding chicks. Birds lose heat mostly through their bare skin, as feathered surfaces are too well insulated for heat loss. Legs and feet dissipate heat well (Baudinette et al. 1976; Drent \& Stonehouse 1971). exposed to air, rather than tucked under the body. Such a posture may increase the risk of 
230 predation if rising takes longer than when both legs are under the body (Anderson \& Williams

231 2010; Carr \& Lima 2012).

232

We divided the colony into 16 areas where we walked slowly to make observations. The

233

234

235

236

237

238

239

240

241

242

243

244

245

246

247

248

249

250

251

252 areas were sampled every five to ten days. Field work was approved by the Institutional Animal

Care and Use Committee of the University of Washington (protocol \#2213-02), and the Province of Chubut, Argentina (Ministerio de Turismo and Ministerio de Desarrollo Territorial y Sectores Productivos, Subsecretaria de Agricultura y Ganadería, Dirección de Fauna y Flora Silvestre, 1194/16-MT).

Analyses

We used binomial (sign) tests with $\mathrm{p}=\mathrm{q}=0.5$ to test whether our findings differed significantly from a 0.5:0.5 ratio (Zar 1984). We also used $\chi^{2}$ tests in a few cases, noted below. We used two-tailed tests and considered $\mathrm{p}<0.05$ significant.

\section{Dominant foot}

One of us (TS) watched 300 penguins walking over obstacles (scales) and recorded the number of penguins that stepped up with each leg, in December 2014 and January 2015. The scales were set on the ground in a dry stream bed that penguins use as a path to travel between their nests and the sea. The scales were in custom-built boxes, $64.8 \mathrm{~cm} \times 32.4 \mathrm{~cm}, 5.7 \mathrm{~cm}$ high, and covered with thick brown vinyl (Fig. 1). We counted only penguins that stopped and then stepped up onto a scale and excluded penguins that continued to walk. Penguins, like people, alternate feet when walking, so if they did not stop, the foot they used might depend on which foot was closest to the scale when they stepped up to cross, and would not reflect any preference. Although penguins with strong lateralization may adjust step length to step with the dominant foot, using only penguins that stopped should be a more sensitive test as penguins with weak 
253 lateralization would be less likely to use the dominant foot if they kept walking. Because of the

254 large number of penguins crossing the scales and the short time we watched, we assumed we

255 counted each penguin only once. During the days we watched penguins crossing, the scales

256 recorded 1272 to 4321 weights each day.

257 We observed 121 penguins using their feet in thermoregulation as we walked around the

258 colony 1 to 17 December 2014 and 30 November to 20 December 2015 (TS and PDB) and

259 another 232 penguins from 15 December 2018 to 4 January 2019 (PDB) (Fig. 2). In 2014 and

260 2015, we searched for penguins using a foot in thermoregulation mostly on hot days, mostly in

261 the middle of the day, when we were most likely to see this behavior. In 2018 , to increase the

262 sample size and see if the pattern held throughout the day, we recorded data in the morning or

263 late afternoon, but not in the middle of the day. When penguins extend a foot, they usually keep

264 the same foot out, sometimes for an hour or more. We recorded if a prone penguin had one or

265 both feet out, and if only one foot was out, which one. Most penguins were unmarked, and not in

266 study nests. It is unlikely that we counted the same penguin more than once because there are a

267 large number of penguins in the colony and we counted penguins in any one area only once per 268 day.

269 We looked for asymmetry in male testes sizes because asymmetric testes may cause

270 circulatory asymmetries, which may, in turn, make one foot more effective for thermoregulation

271 than the other foot. We necropsied 55 adult males found freshly dead in the colony from 2002 to

2722016 and measured the length of their left and right testes. We compared the left and right testes

273 lengths using a paired t-test.

274 Dominant flipper 
curvature and feather wear on the trailing edges of flippers because we could not directly observe

277 penguins foraging (swimming) in the ocean. We collected intact sterna from the remains of dead

278 penguins anywhere in the colony or adjacent beaches in 2014 and 2015 . When the sternum was

disarticulated from the rest of the skeleton without any plumage, we assumed the penguin was an

adult when it died, although we did not know the sex or age of the individual. We found 76

sterna large enough to be from adults. In addition, we found nine carcasses with enough plumage

remaining to determine that the penguins were juveniles when they died $(<1.5$ years of age,

lacking the black and white bands and black faces of adults). We necropsied nine chicks 30 to 60

curvatures in the keel: towards the penguin's right, left, or both (double curve), or none (Fig. 3).

Two people (TS and PDB) examined the keels together. We collected the sterna to prevent

counting the same one more than one time.

A dominant flipper might also result in excessive wear of feathers on one side, if stresses

on the flippers during swimming are not equal. We examined the feathers on the trailing edges of both flippers on 1217 live unbanded adults from October 2008 through February 2018. We used only unbanded penguins because bands caused or worsened feather wear in little penguins (Fallow et al. 2009). Unworn flippers in Magellanic penguins have a narrow band of white feathers on the trailing edges (Fig. 4A). In worn flippers, the white feathers are irregular or missing (Fig. 4B). We did not include penguins if missing feathers appeared to result from an injury rather than wear. We banded 482 of these penguins after measuring them. The rest had unlikely to affect feather wear on flippers. We measured each penguin one time. 
We coded feather wear for each penguin for each flipper as: $1=$ little or no wear, $2=$

299

300

301

302

303

304

305

306

307

308

309

310

311

312

313

314

315

316

317

moderate wear, 3 = severe wear. Several people scored feather wear between 2008 and 2018, but

for each penguin, the same person scored the left and right flippers, and new field workers were trained by PDB or GAR each year. We counted the number of penguins with the same wear on each flipper, the number with more wear on the left flipper, and the number with more wear on the right flipper. We used a binomial test to determine whether left flippers or right flippers had more wear. We also did a likelihood-ratio $\chi^{2}$ (G test) to determine if left flipper wear and right flipper wear were independent of each other, and explored the patterns if they were not. Finally, we used a likelihood-ratio $\chi^{2}$ to determine if symmetry in flipper wear was independent of sex. We recorded the sex of 1071 of the penguins with feather-wear scores, sexing penguins by their bills, which are deeper in males than in females (Boersma et al. 2013). We used the likelihoodratio $\chi^{2}$ because $33.3 \%$ and $40 \%$ of cells in the two tests had expected values $<5$.

\section{Preferred fight orientation}

We predicted that penguins fighting beak to beak would use their left eyes preferentially and hence peck and bite their opponents' left sides more than the right sides, resulting in more blood on the left side of the face. One person (TS) observed fighting penguins, and penguins that had recently fought, opportunistically while walking through the colony, visiting each study area every 5 to 10 days. Dried blood disappeared after about five days on penguins that remained on land and even sooner if a penguin went to the ocean to bathe. It is unlikely that we sampled the same penguin twice. Renison et al. $(2000 ; 2003)$ found that between $15 \%$ and $30 \%$ of penguins fought more than once. We occasionally made video recordings of penguins fighting, and referred to those videos to test our assumption that they fight mostly beak to beak. We saw 215 penguins with blood on their faces from fights. We divided the penguin's face into thirds and 
321 noted whether there was blood in one section (little blood), 2 sections (moderate blood), or all 3

322 sections (a lot of blood), and whether there was blood on only the right side, only the left side, or

323 both sides (Fig. 5). In addition to a binomial test to compare right and left sides of the face, we

324 used a $\chi^{2}$ test to determine if the side of face bloodied was independent of the amount of blood.

325

\section{RESULTS}

327

328

329

330

331

332

333

334

335

336

337

338

339

340

341

342

343

\section{Dominant foot}

We did not find a side preference for stepping up onto an obstacle ( $\mathrm{n}=300$ penguins).

Penguins were equally likely to step up with their left $(n=140$ penguins, $47 \%)$ or right $(n=160$ penguins, $53 \%)$ foot $(\mathrm{p}=0.27)$.

Fewer penguins extended the left foot for thermoregulation than the right foot in 2014 and 2015. We found no preference in which foot was extended in 2018-19. The mixed results may be because the time of day we searched differed between the last season and the first two seasons (see Discussion). In 2014-2015, 39 penguins extended only the left foot, 78 extended only the right foot $(\mathrm{p}<0.001)$, and four penguins extended both feet (Fig. 6A). In 2018-19, we

found no preference in the foot extended: 115 penguins extended only the left foot, 106 extended only the right foot $(\mathrm{p}=0.59)$, and eleven penguins extended both feet (Fig. 6B).

Left testes averaged $3.19 \pm 1.19 \mathrm{~cm}$ (mean \pm standard deviation) and right testes averaged $2.54 \pm 0.99 \mathrm{~cm}(\mathrm{n}=55)$. Left testes were $26 \%$ longer than right testes $\left(\mathrm{t}_{54}=8.4, \mathrm{p}<0.0001\right)$

\section{Dominant flipper}

The sterna of chicks were unossified and the keels were straight $(n=9)$. The sterna of juveniles were ossified and the keels were straight $(n=9)$. Of 76 presumed adult sterna, 46 $(60.5 \%)$ keels curved one direction or the other, 5 (6.5\%) keels curved in both directions (double 
344 curves), and 25 (33\%) keels were straight (Fig. 7). Of the keels that curved one direction, left and

345 right curves were equally likely (22 left, 24 right, $\mathrm{p}=0.88)$.

346 Feather wear on the trailing edges of flippers was uncommon, especially in males. We

347 found feather wear in 179 of 1217 unbanded penguins (15\%). Of the penguins with feather wear,

34845 had equal wear on both flippers. The remaining 134 penguins (11\%) were equally likely to

349 have more wear on the left $(n=74)$ or the right $(n=60)$ flipper $(p=0.26)$.

350 Penguins were more likely than expected to have no feather wear or to have equal feather

351 wear on both flippers (diagonal elements in Table 1; $\mathrm{G}_{4}=249.7, \mathrm{p}<0.001$ ). Wear on one flipper

352 predicted to some extent wear on the other flipper. Penguins with little or no wear on one flipper

353 were less likely than expected to have moderate or severe wear on the other flipper, and penguins

354 with severe wear on one flipper were more likely than expected to have moderate or severe wear 355 on the other flipper (Table 1).

$356 \quad$ Females were twice as likely as males to have feather wear on either or both flippers

$357\left(\chi^{2}(1)=17.4, p<0.001\right)$. Nineteen percent of females had some feather wear compared to $10 \%$

358 of males (Fig. 8A). Females were more likely than males to have more wear on one flipper than

359 on the other flipper (Fig. 8B; $\left.\mathrm{G}_{4}=15.1, \mathrm{p}=0.004\right)$. Proportionately more females $(13.7 \%$ of

$360541)$ than males $(8.1 \%$ of 530) had asymmetrical wear, but among penguins with some wear,

361 proportionately more males $(80 \%$ of 54$)$ than females $(71 \%$ of 104$)$ had asymmetrical wear (Fig.

362 8B). Of the 74 females with asymmetrical wear, 41 had more wear on the left and 33 had more

363 wear on the right (Fig. 8B; $\mathrm{p}=0.42$ ). Of the 43 males with asymmetrical wear, 22 had more wear

364 on the left and 21 had more wear on the right (Fig. 8B; p 1.00).

365 Preferred fight orientation 
367 face than on the left side (Fig. 9). Forty penguins had blood on both sides. Less than half as many

368 penguins had blood only on the left side $(n=55)$ as only on the right side $(n=120, p<0.001)$.

369 The distribution of blood on the face depended on the amount of blood (Fig. $9 ; \chi^{2}(4)=10.7, p=$

370 0.03). Of the penguins with blood on only one side, the tendency to have blood only on the right

371 increased with the amount of blood. Penguins with only a little blood were equally likely to have

372 it on either side $(\mathrm{p}=0.20)$. Penguins with moderate amounts of blood were over three times

373 more likely to have it only on the right than only on the left $(\mathrm{p}<0.001)$. Penguins with a lot of

374 blood were almost five times more likely to have it only on the right $(p=0.002)$.

Penguins pecked and bit while facing each other, with their heads side by side facing the same direction, and at every angle in between (Fig. 10). In any orientation except directly face to

377 face, if the more aggressive penguin looks with its left eye, it sees the right side of the other penguin's face. Our observations and videos of penguin fights showed fighting directly face to face was not always the dominant orientation. Assuming the more aggressive penguin gets less blood on its face than the penguin it attacks, the observed pattern should be more blood on the 381 right side of the face (Fig. 10), as we found.

\section{DISCUSSION}

Lateralization in Magellanic penguins depended on the behavior we observed. We found evidence for dominant flippers in individual penguins, but not in the population; approximately half the penguins were right sided and half left sided. We could not test for individual preferences in the other behaviors (stepping up, thermoregulation, and fights) as we only had one observation per penguin. We did not find a dominant foot in stepping up for the population. We 
389 found a significant bias in foot use for thermoregulation in 2014 and 2015, likely because we

390 concentrated our effort during the heat of the day. When we looked for extended feet in 2018-19,

391 we did not find a preference, likely because we looked early and late in the day. We found

392 lateralization in fight behavior, the only social behavior we tested; the left eye was used for

393 aggression, consistent with other vertebrate species.

394 Dominant foot

395 Penguins at Punta Tombo walk up to a kilometer to transit between their nests and the

396 beach (Rebstock, Boersma \& García-Borboroglu 2016; Walker, Boersma \& Wingfield 2004),

397 and encounter many obstacles on land, including rocks, branches, and burrow entrances or

398 depressions in the ground. We found no dominant foot for stepping up onto an obstacle in the

399 population. It is possible that individual penguins have a dominant foot, but approximately half

400 are right footed and half left footed.

401 Stepping is not always a reliable indicator of a side preference. Stepping up is an

402 unskilled task; skilled tasks (e.g., kicking a ball) are more likely to show a dominant foot in

403 humans (Schneiders et al. 2010). Fewer than half of 32 dogs showed a paw preference in

404 stepping down a step in one study (Wells et al. 2018), but the front paw dogs first used in

405 stepping after standing still was a reliable indicator of a dominant paw in another study

406 (Tomkins, Thomson \& McGreevy 2010).

407 We predicted that we would find a preferred foot used in thermoregulation in the

408 population because of circulatory asymmetries. If one foot receives more blood than the other

409 foot, that foot would be more efficient to use for thermoregulation. Well-developed ova and the

410 shell gland, on the left side of female birds, use a lot of blood (Sturkie 1986). As in many bird

411 species, we found that the testes of breeding male Magellanic penguins are more developed on 
412 the left side than on the right side. The right foot may receive more blood than the left foot

413 because the reproductive organs are on the left side. Asymmetries occur in the circulatory

414 systems of birds (Odlind 1978; Porter \& Witmer 2016), including blood flow to the feet

415 (Bernstein 1974).

416 We found a preference to extend the right foot in 2014 and 2015 but no preference in

417 2018-19. We suggest that temperature explains the mixed results because we looked for penguins

418 thermoregulating specifically during hot periods in 2014 and 2015, but during mornings and

419 evenings in 2018-19. How hot the penguin is may influence which foot is extended. If

420 circulatory asymmetries drive which foot is extended, penguins should use the most efficient

421 foot, or both feet, on the hottest days. Body temperature in African penguins Spheniscus

422 demersus was higher on hot sunny days than on cool overcast days, and higher in the middle of

423 the day than early morning or evening (Frost, Siegfried \& Burger 1976). It may not matter which

424 foot a penguin uses for thermoregulation on cooler days or at cooler times of day, when its body

425 temperature is lower and it does not need to dump heat rapidly.

Although extending both legs and feet would be even more efficient for losing heat, this

427

428

429

430

431

432

433

434

was rare. Having both feet extended would likely increase the time it takes a penguin to stand up much more than extending only one leg. It also may be more effective to stand and pant when very hot (Boersma 1975).

Dominant flipper

We found evidence that some individual penguins have a dominant flipper. Asymmetry in wings is maladaptive in flying birds and may result from fluctuating asymmetries or imperfect bilateral development (Balmford, Jones \& Thomas 1993; Brown \& Bomberger Brown 1998). Penguins "fly" through the water using their flippers to counteract their positive buoyancy when 
435 descending during a dive (Mattern et al. 2018). The advantages of flipper asymmetry in water, a 436 dense medium, may outweigh the disadvantages. MacNeilage (2014) hypothesized that side

437 biases are common in marine mammals because water does not provide support for the reactive 438 component in movement. A sudden change in movement, such as a turn, requires support for the 439 reaction forces ("equal and opposite reaction"). For example, a running person pushes against the

440 ground with the left foot to turn right. When a swimming animal makes a sudden turn, the water 441 provides little resistance. Air also does not support the reaction forces, but water is much denser 442 than air and resists sudden movements more than air (MacNeilage 2014). Hence, morphological 443 asymmetries in the keels and flippers may help penguins manoeuver more efficiently in the 444 water.

445 We assumed that the behavior (swimming with a dominant flipper) was the cause rather 446 than the effect of the morphological asymmetries because we found the keel asymmetries in 447 adults, but not in chicks or juveniles. The curve likely results from uneven forces on the bone 448 (Currey 2003; Shaw \& Stock 2009). Assuming the pectoralis and supracoracoideus muscles on 449 the dominant side are thicker (more muscle fibers) than those on the opposite side, the pull on the 450 keel is asymmetric, resulting in uneven forces and bone remodeling. A curved surface is stronger than a flat surface, so the curve may help resist the unequal pull. The curve overlaps the section 452 of the keel where the bone is thinnest (Fig. 11). The curvature also increases the surface area for 453 attachment of muscles, without increasing the length or depth of the keel.

Keels on sterna that curved one direction $(60.5 \%)$ were much more common than asymmetrical feather wear on the flippers (11\%). Keel curvature likely accumulates over the life of the penguin. The sternum is among the last bones to ossify in birds, generally after hatching

457 (Maxwell \& Harrison 2008; Mitgutsch et al. 2011), and the pectoralis muscles are relatively 
458 small until the chick begins exercising its wings prior to fledging, or begins flying (Bennett

459 2008; Carrier \& Leon 1990). Before the pectoralis muscles develop fully, asymmetrical forces on

460 the keel would not be great enough to cause remodeling or deformation of the bone. Magellanic

461 penguin chicks exercise their flippers by rapidly flapping them only a few weeks before fledging.

462 Curved keels were not present in juveniles suggesting more than one year at sea is needed for a

463 keel to accumulate a noticeable curve. Feather wear on flippers, in contrast, accumulates over

464 one year and then is eliminated following the molt as the vast majority of penguins molt

465 annually, replacing worn feathers (Boersma et al. 2013). The time for the side bias to affect the

466 feathers is only one year, relatively short compared to the lifetime of the bird for the keel

467 curvature.

468 Females were more likely than males to have feather wear and asymmetrical feather wear 469 on their flippers. Females are smaller than males on average (Boersma et al. 2013) and have a 470 narrower isotopic niche width (eat fewer species of prey) (Silva et al. 2014). Smaller penguins 471 cannot dive as deeply or as long as larger penguins (Walker \& Boersma 2003). Overwinter

472 mortality is higher in females than in males (Vanstreels et al. 2013), especially in years when

473 overall mortality is high and prey availability is presumably low (Gownaris \& Boersma 2019).

474 Hence, females likely work harder than males when foraging, leading to greater feather wear on 475 females' flippers.

476

477

478

479

480

\section{Preferred fight orientation}

We found evidence for a preferred fighting orientation in Magellanic penguins, consistent with the more aggressive penguin in a fight using its left eye and attacking the right side of the opponent. The result was opposite our prediction because we overestimated the amount of time penguins fight facing each other (bill-to-bill) and did not take into account the greater amount of 
481 blood likely on the face of the less aggressive penguin compared to the more aggressive penguin.

482 Animals in a wide range of taxa use the left eye (or left antenna) preferentially in aggressive

483 interactions with conspecifics (Bisazza, Rogers \& Vallortigara 1998; Hews \& Worthington 2001;

484 Rogers, Frasnelli \& Versace 2016).

485 Penguins' fight behavior is also consistent with evidence that lateralization is more likely 486 in a population in social contexts than in individual contexts (Ghirlanda, Frasnelli \& Vallortigara

487 2009; Ghirlanda \& Vallortigara 2004; Rogers, Frasnelli \& Versace 2016). Aggressive

488 interactions are more strongly lateralized than nonaggressive interactions in many species

489 (Deckel 1995; Rogers, Frasnelli \& Versace 2016).

490

Asymmetries in circulation could contribute to the pattern we found. In double-crested

491

492

493

494

495

496

497

498

499

500

501

502

503

cormorants (Phalacrocorax auritus), the left palatine artery is larger than the right palatine artery

(Porter \& Witmer 2016). If an artery supplying the right side of the face is larger than the

corresponding artery on the left in Magellanic penguins, they would bleed more on the right when cut.

The percentages of penguins with blood on both sides of the face and only on the right side of the face increased as the amount of blood increased. We would expect to see more blood on both sides, as the more blood present, the less likely it is to be concentrated in a small area of the face. The proportion of penguins with blood only on the right side increased with the amount of blood. This pattern is consistent with the tendency to use the left eye more as aggression increases (Deckel 1995), and more blood likely indicates more aggression and more intense fights. Magellanic penguin fights that lasted longer and were in higher quality nests resulted in more cuts to the face (Renison et al. 2006). 


\section{CONCLUSIONS}

505 Magellanic penguins join the growing list of species that show evidence of lateralization

506 in the wild. The lateralization depended on the behavior or context, and was sometimes evident

507 for individuals, but not for the population. Penguins lack the behaviors typically tested in birds to

508 look for a dominate foot, such as standing on one foot or manipulating food with a foot (Randler

509 2007; Rogers 2009). We found no lateralization for the population when stepping up. Population

510 lateralization in the use of a foot for thermoregulation was sometimes evident. We suggest that

511 penguins show lateralization at hotter temperatures but not when cooler. We found over half of

512 adult Magellanic penguin keels showed morphological evidence of a dominant flipper, but the

513 population did not show any flipper preference. Stepping up, thermoregulating, and swimming

514 are individual behaviors. In fights, the only social behavior we tested, attacking Magellanic

515 penguins are likely to use the left eye, resulting in more blood on the right side of the face of the

516 opponent (the less aggressive penguin). The preference for using the left eye in aggressive

517 interactions is found in many other species (Bisazza, Rogers \& Vallortigara 1998; Rogers 2008)

518 and shows specialization of the brain hemispheres (Rogers 2017). Our results are also consistent

519 with other studies showing lateralization of a population is more likely in social contexts

520 (Vallortigara \& Rogers 2005). Like many other species, Magellanic penguins show context-

521 specific lateralization.

522

\section{ACKNOWLEGEMENTS}

524 Research at Punta Tombo was carried out under a joint agreement between the Wildlife

525 Conservation Society and the Office of Tourism, Province of Chubut, Argentina. We thank the

526 Province of Chubut and particularly the Offices of Tourism and of Flora and Fauna, and the 
527 National Scientific and Technical Research Council of Argentina for permits and/or logistical

528 support. The La Regina family allowed access to the penguins breeding on their land. We thank

529 the La Regina family, Carlos García, William Conway, Graham Harris, Patricia Harris, Carol

530 Passera, Carlos Passera, and Centro Nacional Patagónico, Argentina (CENPAT), and key

531 wardens for logistical support and help over the 35 years of study. We are grateful to the many

532 students and field volunteers who collected data. Discussions with Adam Summers helped

533 clarify the predictions and their mechanisms. Gordon Orians, Eric Wagner, and two anonymous

534 reviewers improved the manuscript.

535

536

537

538

539

540

541

542

543

544

545

546

547

548

549

550

551

552

553

554

555

556

557

558

559

560

561

562

\section{REFERENCES}

Anderson MJ, and Williams SA. 2010. Why do flamingos stand on one leg? Zoo Biology 29:365-374. doi: 10.1002/zoo.20266.

Balmford A, Jones IL, and Thomas ALR. 1993. On avian asymmetry: Evidence of natural selection for symmetrical tails and wings in birds. Proceedings of the Royal Society B: Biological Sciences 252:245-251.

Baudinette RV, Loveridge JP, Wilson KJ, Mills CD, and Schmidt-Nielsen K. 1976. Heat loss from feet of herring gulls at rest and during flight. American Journal of Physiology 230:920-924. doi: 10.1152/ajplegacy.1976.230.4.920.

Bell ATA, and Niven JE. 2016. Strength of forelimb lateralization predicts motor errors in an insect. Biology Letters 12:20160547. doi: 10.1098/rsbl.2016.0547.

Bennett MB. 2008. Post-hatching growth and development of the pectoral and pelvic limbs in the black noddy, Anous minutus. Comparative Biochemistry and Physiology Part A: Molecular \& Integrative Physiology 150:159-168. doi: 10.1016/j.cbpa.2006.06.011.

Berlincourt M, and Arnould JPY. 2014. At-sea associations in foraging little penguins. PLoS ONE 9:e105065. doi: 10.1371/journal.pone.0105065.

Bernstein MH. 1974. Vascular responses and foot temperature in pigeons. American Journal of Physiology 226:1350-1355. doi: 10.1152/ajplegacy.1974.226.6.1350.

Birkhead TR, Fletcher F, and Pellatt EJ. 1998. Testes asymmetry, condition and sexual selection in birds: an experimental test. Proceedings of the Royal Society of London Series B: Biological Sciences 265:1185-1189. doi: 10.1098/rspb.1998.0417.

Bisazza A, Cantalupo C, Capocchiano M, and Vallortigara G. 2000. Population lateralisation and social behaviour: A study with 16 species of fish. Laterality 5:269-284. doi: 10.1080/135765000406111.

Bisazza A, Rogers $L$, and Vallortigara G. 1998. The origins of cerebral asymmetry: a review of evidence of behavioural and brain lateralization in fishes, reptiles and amphibians. Neuroscience \& Biobehavioral Reviews 22:411-426. doi: 10.1016/S0149-7634(97)00050-X.

Peer) reviewing PDF | (2018:10:31803:2:0:NEW 2 Apr 2019) 
563

Boersma D. 1975. Adaptations of Galápagos penguins for life in two different environments. In: Stonehouse B, ed. The Biology of Penguins. London: The MacMillan Press Ltd., 101-114.

Boersma PD, Frere E, Kane O, Pozzi LM, Pütz K, Raya Rey A, Rebstock GA, Simeone A, Smith J, Van Buren A, Yorio P, and García Borboroglu P. 2013. Magellanic penguin (Spheniscus magellanicus). In: García Borboroglu P, and Boersma PD, eds. Penguins: natural history and conservation. Seattle, WA: University of Washington Press, 233-263.

Boersma PD, and Rebstock GA. 2009. Foraging distance affects reproductive success in Magellanic penguins. Marine Ecology Progress Series 375:263-275. doi: 10.3354/meps07753.

Boersma PD, and Rebstock GA. 2010. Effects of double bands on Magellanic Penguins. Journal of Field Ornithology 81:195-205. doi: 10.1111/j.1557-9263.2010.00277.x.

Boersma PD, and Rebstock GA. 2014. Climate change increases reproductive failure in Magellanic penguins. PLOS ONE 9:e85602. doi: 10.1371/journal.pone.0085602.

Boersma PD, Stokes DL, and Yorio PM. 1990. Reproductive variability and historical change of Magellanic penguins (Spheniscus magellanicus) at Punta Tombo, Argentina. In: Davis L, and Darby J, eds. Penguin biology. San Diego, CA: Academic Press, 15-43.

Brown CR, and Bomberger Brown M. 1998. Intense natural selection on body size and wing and tail asymmetry in cliff swallows during severe weather. Evolution 52:1461-1475. doi: $10.2307 / 2411315$.

Carr JM, and Lima SL. 2012. Heat-conserving postures hinder escape: a thermoregulation-predation trade-off in wintering birds. Behavioral Ecology 23:434-441. doi: 10.1093/beheco/arr208.

Carrier D, and Leon LR. 1990. Skeletal growth and function in the California gull (Larus californicus). Journal of Zoology 222:375-389. doi: 10.1111/j.1469-7998.1990.tb04039.x.

Clark JA, and Boersma PD. 2006. Southern elephant seal, Mirounga leonina, kills Magellanic penguins, Spheniscus magellanicus, on land. Marine Mammal Science 22:222-225. doi: 10.1111/j.17487692.2006.00017.x.

Currey JD. 2003. The many adaptations of bone. Journal of Biomechanics 36:1487-1495. doi: 10.1016/S0021-9290(03)00124-6.

Dadda M, Koolhaas WH, and Domenici P. 2010. Behavioural asymmetry affects escape performance in a teleost fish. Biology Letters 6:414-417. doi: 10.1098/rsbl.2009.0904.

Deckel AW. 1995. Laterality of aggressive responses in Anolis. Journal of Experimental Zoology 272:194200. doi: $10.1002 /$ jez.1402720304.

Domenici P. 2010. Context-dependent variability in the components of fish escape response: integrating locomotor performance and behavior. Journal of Experimental Zoology Part A: Ecological Genetics and Physiology 313A:59-79. doi: 10.1002/jez.580.

Drent RH, and Stonehouse B. 1971. Thermoregulatory responses of the peruvian penguin, Spheniscus humboldti. Comparative Biochemistry and Physiology Part A: Physiology 40:689-710. doi: 10.1016/0300-9629(71)90254-4.

Fallow PM, Chiaradia A, Ropert-Coudert Y, Kato A, and Reina RD. 2009. Flipper bands modify the shortterm diving behavior of little penguins. Journal of Wildlife Management 73:1348-1354. doi: 10.2193/2008-146.

Frasnelli E, Vallortigara G, and Rogers LJ. 2012. Left-right asymmetries of behaviour and nervous system in invertebrates. Neuroscience \& Biobehavioral Reviews 36:1273-1291. doi: 10.1016/j.neubiorev.2012.02.006.

Frere E, Gandini P, and Lichtschein V. 1996. Variación latitudinal en la dieta del pingüino de Magallanes (Spheniscus magellanicus) en la costa Patagónica, Argentina. Ornitología Neotropical 7:35-41.

Frere E, Millones A, Morgenthaler A, Travaini A, and Gandini P. 2010. High predation rates by pumas on Magellanic Penguin adults: New conflicts in coastal protected areas in Argentina. 1st World Seabird Conference Poster Session 2. Victoria, British Columbia, Canada.

Peer) reviewing PDF | (2018:10:31803:2:0:NEW 2 Apr 2019) 
611

612

613

614

615

616

617

618

619

620

621

622

623

624

625

626

627

628

629

630

631

632

633

634

635

636

637

638

639

640

641

642

643

644

645

646

647

648

649

650

651

652

653

654

655

656

657

Frost PGH, Siegfried WR, and Burger AE. 1976. Behavioural adaptations of the Jackass penguins, Spheniscus demersus to a hot, arid environment. Journal of Zoology 179:165-187. doi: 10.1111/j.1469-7998.1976.tb02289.x.

Ghirlanda S, Frasnelli E, and Vallortigara G. 2009. Intraspecific competition and coordination in the evolution of lateralization. Philosophical Transactions of the Royal Society B: Biological Sciences 364:861-866. doi: 10.1098/rstb.2008.0227.

Ghirlanda S, and Vallortigara G. 2004. The evolution of brain lateralization: a game-theoretical analysis of population structure. Proceedings of the Royal Society of London Series B: Biological Sciences 271:853-857. doi: 10.1098/rspb.2003.2669.

Gill FB. 1995. Ornithology. New York: W. H. Freeman and Company.

Gómez-Laich A, Yoda K, and Quintana F. 2018. Insights into the foraging behavior of Magellanic penguins (Spheniscus magellanicus). Waterbirds 41:332-336. doi: 10.1675/063.041.0315.

Gownaris NJ, and Boersma PD. 2019. Sex-biased survival contributes to population decline in a longlived seabird, the Magellanic penguin. Ecological Applications 29:e01826. doi: 10.1002/eap.1826.

Harris LJ. 1989. Footedness in parrots: three centuries of research, theory, and mere surmise. Canadian Journal of Psychology 43:369-396. doi: 10.1037/h0084228.

Hews DK, and Worthington RA. 2001. Fighting from the right side of the brain: left visual field preference during aggression in free-ranging male tree lizards (Urosaurus ornatus). Brain, Behavior and Evolution 58:356-361. doi: 10.1159/000057576.

Huurnink A, Fransz DP, Kingma I, Hupperets MDW, and van Dieën JH. 2014. The effect of leg preference on postural stability in healthy athletes. Journal of Biomechanics 47:308-312. doi: 10.1016/j.jbiomech.2013.10.002.

Jehl JR, Jr. 1974. The distribution and ecology of marine birds over the continental shelf of Argentina in winter. Transactions of the San Diego Society of Natural History 17:217-234.

Kurvers RHJM, Krause S, Viblanc PE, Herbert-Read JE, Zaslansky P, Domenici P, Marras S, Steffensen JF, Svendsen MBS, Wilson ADM, Couillaud P, Boswell KM, and Krause J. 2017. The evolution of lateralization in group hunting sailfish. Current Biology 27:521-526. doi: 10.1016/j.cub.2016.12.044.

MacNeilage PF. 2014. Evolution of the strongest vertebrate rightward action asymmetries: Marine mammal sidedness and human handedness. Psychological Bulletin 140:587-609. doi: 10.1037/a0034298.

Mattern T, McPherson MD, Ellenberg U, van Heezik Y, and Seddon PJ. 2018. High definition video loggers provide new insights into behaviour, physiology, and the oceanic habitat of a marine predator, the yellow-eyed penguin. PeerJ 6:e5459. doi: 10.7717/peerj.5459.

Maxwell EE, and Harrison LB. 2008. Ossification sequence of the common tern (Sterna hirundo) and its implications for the interrelationships of the Lari (Aves, Charadriiformes). Journal of Morphology 269:1056-1072. doi: 10.1002/jmor.10633.

McInnes AM, McGeorge C, Ginsberg S, Pichegru L, and Pistorius PA. 2017. Group foraging increases foraging efficiency in a piscivorous diver, the African penguin. Royal Society Open Science 4:170918. doi: 10.1098/rsos.170918.

Mitgutsch C, Wimmer C, Sánchez-Villagra MR, Hahnloser R, and Schneider RA. 2011. Timing of ossification in duck, quail, and zebra finch: intraspecific variation, heterochronies, and life history evolution. Zoological Science 28:491-500. doi: 10.2108/zsj.28.491.

Odlind B. 1978. Blood flow distribution in the renal portal system of the intact hen. A study of a venous system using microspheres. Acta Physiologica Scandinavica 102:342-356. doi: 10.1111/j.17481716.1978.tb06081.x.

Peer) reviewing PDF | (2018:10:31803:2:0:NEW 2 Apr 2019) 
658

659

660

661

662

663

664

665

666

667

668

669

670

671

672

673

674

675

676

677

678

679

680

681

682

683

684

685

686

687

688

689

690

691

692

693

694

695

696

697

698

699

700

701

702

703

Porter WMR, and Witmer LM. 2016. Avian cephalic vascular anatomy, sites of thermal exchange, and the rete ophthalmicum. The Anatomical Record 299:1461-1486. doi: 10.1002/ar.23375.

Pütz K, Ingham RJ, and Smith JG. 2000. Satellite tracking of the winter migration of Magellanic Penguins Spheniscus magellanicus breeding in the Falkland Islands. Ibis 142:614-622. doi: 10.1111/j.1474919x.2000.tb04461.x.

Randler C. 2007. Foot preferences during resting in wildfowl and waders. Laterality 12:191-197. doi: $10.1080 / 13576500601005776$.

Rebstock GA, Boersma PD, and García-Borboroglu P. 2016. Changes in habitat use and nesting density in a declining seabird colony. Population Ecology 58:105-119. doi: 10.1007/s10144-015-0523-0.

Renison D. 2000. Comportamiento agresivo del pingüino de Magallanes (Spheniscus magellanicus): un enfoque ecológico. Doctorado en Ciencias Biológicas. Dissertation. Universidad Nacional de Córdoba.

Renison D, Boersma D, and Martella MB. 2002. Winning and losing: causes for variability in outcome of fights in male Magellanic penguins (Spheniscus magellanicus). Behavioral Ecology 13:462-466. doi: 10.1093/beheco/13.4.462.

Renison D, Boersma D, and Martella MB. 2003. Fighting in female Magellanic Penguins: when, why, and who wins? Wilson Bulletin 115:58-63.

Renison D, Boersma PD, Van Buren AN, and Martella MB. 2006. Agonistic behavior in wild male Magellanic penguins: when and how do they interact? Journal of Ethology 24:189-193. doi: 10.1007/s10164-005-0180-4.

Rogers L. 2008. Development and function of lateralization in the avian brain. Brain Research Bulletin 76:235-244. doi: 10.1016/j.brainresbull.2008.02.001.

Rogers L. 2009. Hand and paw preferences in relation to the lateralized brain. Philosophical Transactions of the Royal Society B: Biological Sciences 364:943-954. doi: 10.1098/rstb.2008.0225.

Rogers L. 2017. A matter of degree: strength of brain asymmetry and behaviour. Symmetry 9:57. doi: $10.3390 /$ sym 9040057.

Rogers L, Frasnelli E, and Versace E. 2016. Lateralized antennal control of aggression and sex differences in red mason bees, Osmia bicornis. Scientific Reports 6:29411. doi: $10.1038 /$ srep29411.

Schiffner I, and Srinivasan MV. 2013. Behavioural lateralization in Budgerigars varies with the task and the individual. PLOS ONE 8:e82670. doi: 10.1371/journal.pone.0082670.

Schneiders AG, Sullivan SJ, O'Malley KJ, Clarke SV, Knappstein SA, and Taylor L. 2010. A Valid and Reliable Clinical Determination of Footedness. $P M \& R$ 2:835-841. doi: 10.1016/j.pmrj.2010.06.004.

Shaw CN, and Stock JT. 2009. Habitual throwing and swimming correspond with upper limb diaphyseal strength and shape in modern human athletes. American Journal of Physical Anthropology 140:160-172. doi: 10.1002/ajpa.21063.

Silva L, Saporit F, Vales D, Tavares M, Gandini P, Crespo EA, and Cardona L. 2014. Differences in diet composition and foraging patterns between sexes of the Magellanic penguin (Spheniscus magellanicus) during the non-breeding period as revealed by $\delta^{13} \mathrm{C}$ and $\delta^{15} \mathrm{~N}$ values in feathers and bone. Marine Biology 161:1195-1206. doi: 10.1007/s00227-014-2410-1.

Stokes DL, and Boersma PD. 1991. Effects of substrate on the distribution of Magellanic Penguin (Spheniscus magellanicus) burrows. The Auk 108:923-933.

Stokes DL, and Boersma PD. 1998. Nest-site characteristics and reproductive success in Magellanic penguins (Spheniscus magellanicus). The Auk 115:34-49. doi: 10.2307/4089109.

Peer) reviewing PDF | (2018:10:31803:2:0:NEW 2 Apr 2019) 
704

705

706

707

708

709

710

711

712

713

714

715

716

717

718

719

720

721

722

723

724

725

726

727

728

729

730

731

732

733

734

735

736

737

738

739

740

741

742

743

744

745

746

747

748
Stokes DL, Boersma PD, de Casenave JL, and García-Borboroglu P. 2014. Conservation of migratory Magellanic penguins requires marine zoning. Biological Conservation 170:151-161. doi: 10.1016/j.biocon.2013.12.024.

Sturkie PD. 1986. Heart and circulation: anatomy, hemodynamics, blood pressure, blood flow. In: Sturkie PD, ed. Avian Physiology. 4 ed. New York: Spring-Verlag, 130-166.

Sutton GJ, Hoskins AJ, and Arnould JPY. 2015. Benefits of group foraging depend on prey type in a small marine predator, the little penguin. PLOS ONE 10:e0144297. doi: 10.1371/journal.pone.0144297.

Thiebot J-B, Arnould JPY, Gómez-Laich A, Ito K, Kato A, Mattern T, Mitamura H, Noda T, Poupart T, Quintana F, Raclot T, Ropert-Coudert Y, Sala JE, Seddon PJ, Sutton GJ, Yoda K, and Takahashi A. 2017. Jellyfish and other gelata as food for four penguin species - insights from predator-borne videos. Frontiers in Ecology and the Environment 15:437-441. doi: 10.1002/fee.1529.

Tomkins LM, Thomson PC, and McGreevy PD. 2010. First-stepping Test as a measure of motor laterality in dogs (Canis familiaris). Journal of Veterinary Behavior: Clinical Applications and Research 5:247-255. doi: 10.1016/j.jveb.2010.03.001.

Tommasi L, and Vallortigara G. 1999. Footedness in binocular and monocular chicks. Laterality 4:89-95. doi: $10.1080 / 135765099397132$.

Vallortigara G. 2015. Handedness: What Kangaroos Tell Us about Our Lopsided Brains. Current Biology 25:R672-R674. doi: 10.1016/j.cub.2015.06.036.

Vallortigara G, Chiandetti C, and Sovrano VA. 2011. Brain asymmetry (animal). Cognitive Science 2:146157. doi: $10.1002 /$ wcs. 100.

Vallortigara G, and Rogers L. 2005. Survival with an asymmetrical brain: advantages and disadvantages of cerebral lateralization. Behavioral and Brain Sciences 28:575-589. doi: 10.1017/S0140525X05000105.

Vanstreels RET, Corrado Adornes A, Lima Canabarro P, Ruoppolo V, Amaku M, Pinho da Silva-Filho R, and Catão-Dias JL. 2013. Female-biased mortality of Magellanic Penguins (Spheniscus magellanicus) on the wintering grounds. Emu 113:128-134. doi: 10.1071/MU12060.

Versace E, and Vallortigara G. 2015. Forelimb preferences in human beings and other species: multiple models for testing hypotheses on lateralization. Frontiers in Psychology 6 doi: 10.3389/fpsyg.2015.00233.

Walker BG, and Boersma PD. 2003. Diving behavior of Magellanic penguins (Spheniscus magellanicus) at Punta Tombo, Argentina. Canadian Journal of Zoology 81:1471-1483. doi: 10.1139/z03-142.

Walker BG, Boersma PD, and Wingfield JC. 2004. Physiological condition in Magellanic Penguins: does it matter if you have to walk a long way to your nest? Condor 106:696-701.

Wells DL, Hepper PG, Milligan ADS, and Barnard S. 2018. Stability of motor bias in the domestic dog, Canis familiaris. Behavioural Processes 149:1-7. doi: 10.1016/j.beproc.2018.01.012.

Wilson RP, Scolaro JA, Grémillet D, Kierspel MAM, Laurenti S, Upton J, Gallelli H, Quintana F, Frere E, Müller G, Straten MT, and Zimmer I. 2005. How do Magellanic penguins cope with variability in their access to prey? Ecological Monographs 75:379-401. doi: 10.1890/04-1238.

Wilson RP, and Wilson M-PT. 1990. Foraging ecology of breeding Spheniscus penguins. In: Davis LS, and Darby JT, eds. Penguin Biology. San Diego, CA: Academic Press, 181-206.

Zanón Martínez JI, Travaini A, Zapata S, Procopio D, and Santillán Á. 2012. The ecological role of native and introduced species in the diet of the puma Puma concolor in southern Patagonia. Oryx 46:106-111. doi: 10.1017/S0030605310001821.

Zar JH. 1984. Biostatistical Analysis. Englewood Cliffs, NJ: Prentice Hall. 


\section{Figure 1}

Magellanic penguins crossing obstacles (scales) in their path.

We recorded whether a penguin that stopped then stepped onto the scale with its right or left foot. Photo credit: Clayton Gravelle.

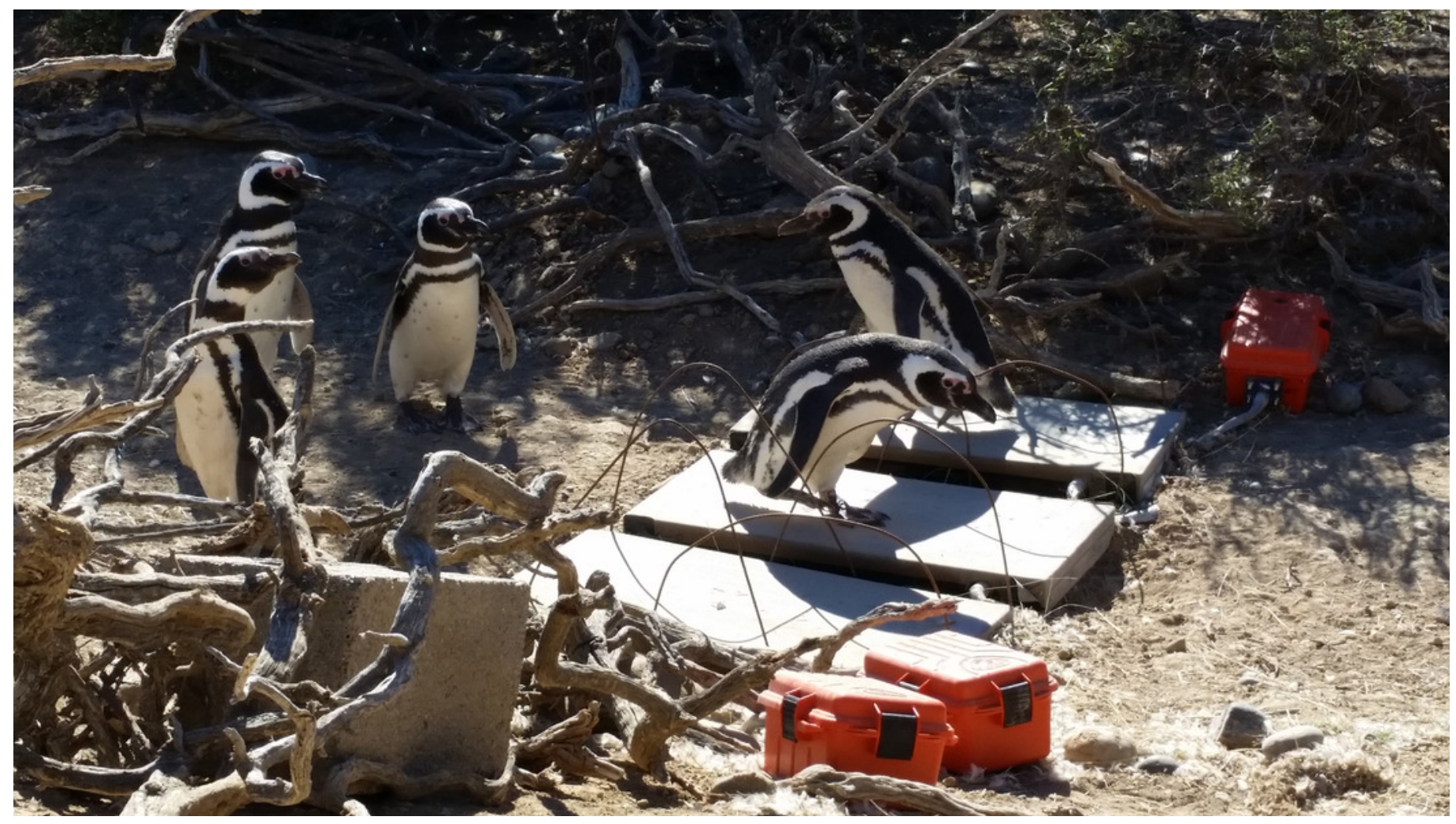


Figure 2

A Magellanic penguin using its extended right foot for thermoregulation on a hot day.

Photo credit: Dee Boersma.

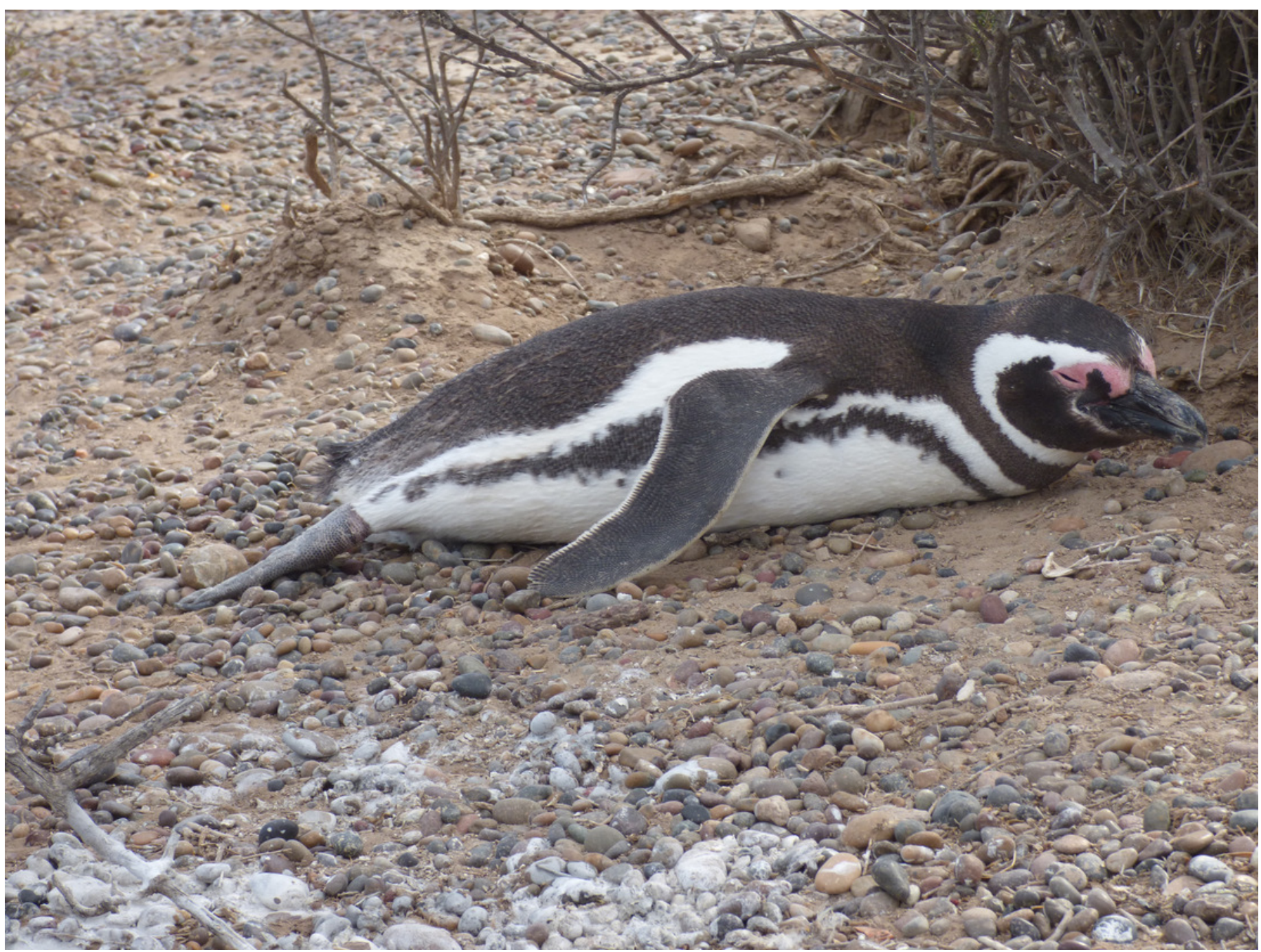




\section{Figure 3}

Curvature of keel (carina) on the sterna of Magellanic penguins.

Anterior is towards the top of the figure. A) Two sterna of presumed adult penguins. The keel on the left sternum has a curve to the penguin's right; the keel on the right sternum curves to the penguin's left. B) A juvenile sternum as evidenced by the plumage remaining on the carcass. The keel lacks a curve. Photo credit: Dee Boersma

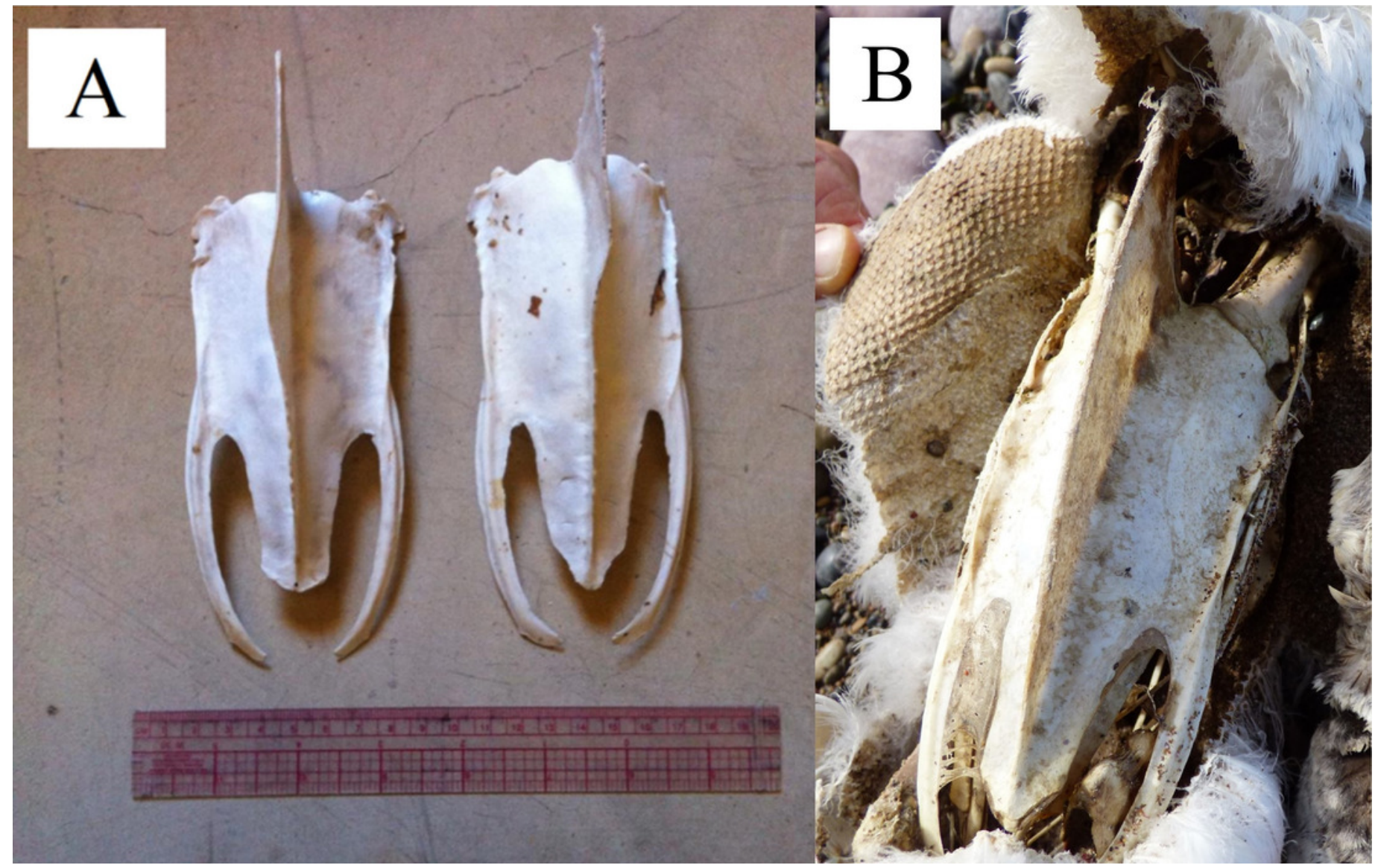




\section{Figure 4}

Feather wear on the trailing edges of adult Magellanic penguins' flippers.

A) Normal white feathers on trailing edge of flipper. B) Worn feathers on trailing edge of flipper. Photo credit: Dee Boersma.

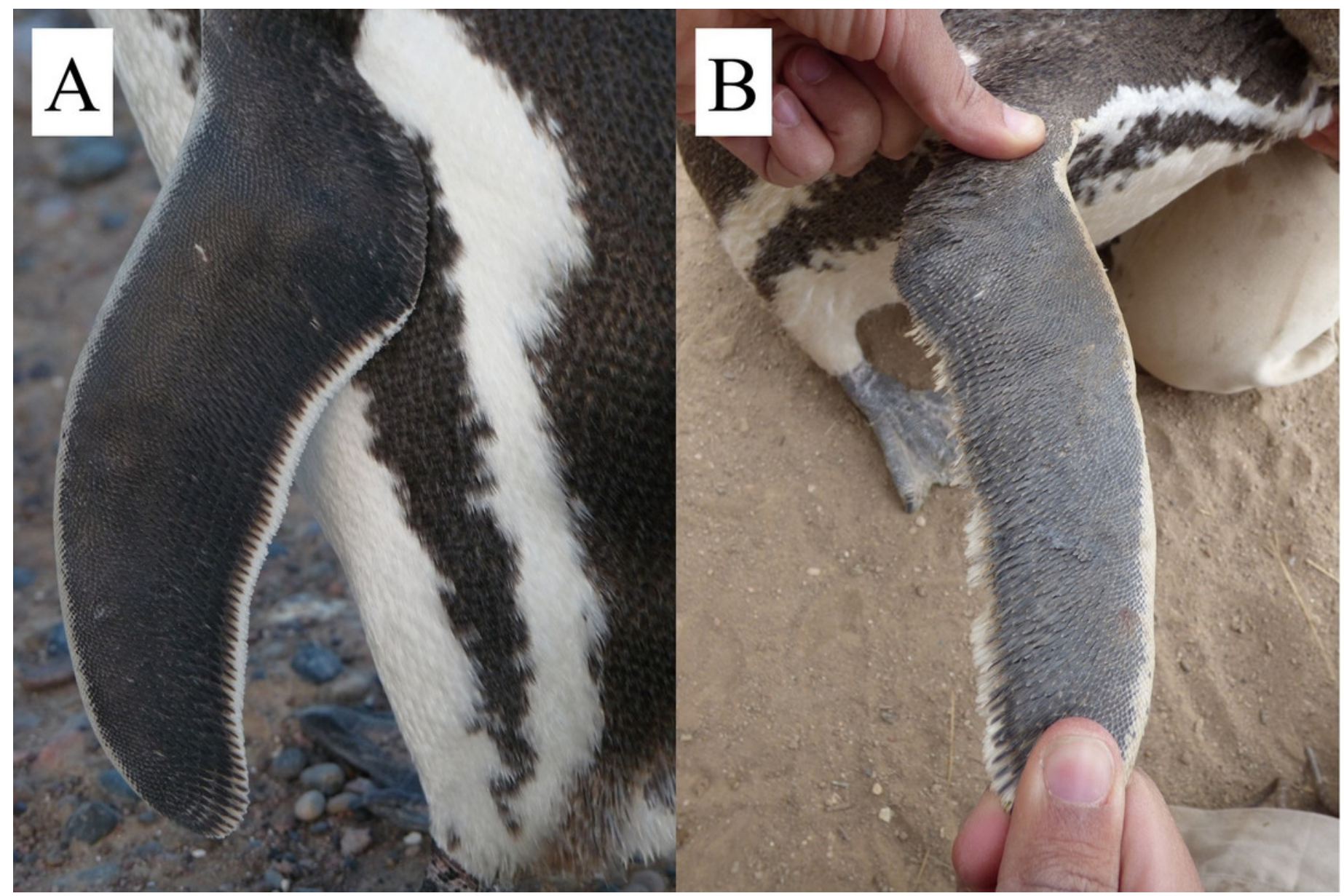




\section{Figure 5}

Scoring of blood on the face of a Magellanic penguin that recently fought another penguin.

We scored blood on up to $1 / 3$ of the face as "little", from $1 / 3$ up to $2 / 3$ of the face as "moderate", and more than 2/3 of the face as "a lot" of blood. We also noted whether there was blood only on the right side, only on the left side, or on both sides. Photo credit: Dee Boersma.

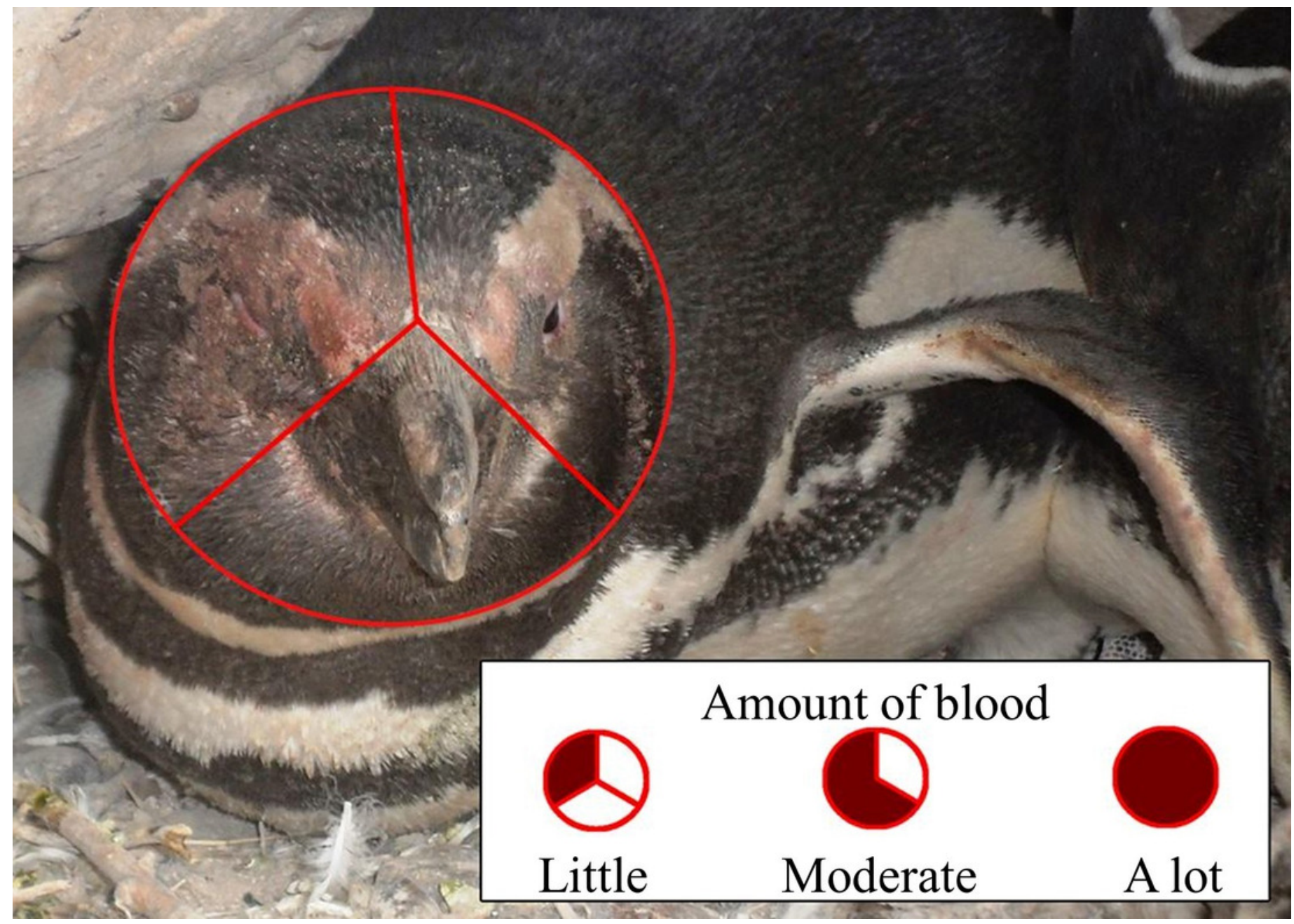




\section{Figure 6}

Magellanic penguins used the right foot preferentially in thermoregulation in two seasons, but not in a third season.

A) Twice as many penguins extended the right foot for thermoregulation as the left foot on hot days in the 2014 and 2015 breeding seasons. Four penguins extended both feet. B) Approximately half of the penguins in the 2018 breeding season extended the right foot and half the left foot. Eleven penguins extended both feet. We recorded data on all days that we saw thermoregulation behaviour, and only in the mornings and late afternoons. 

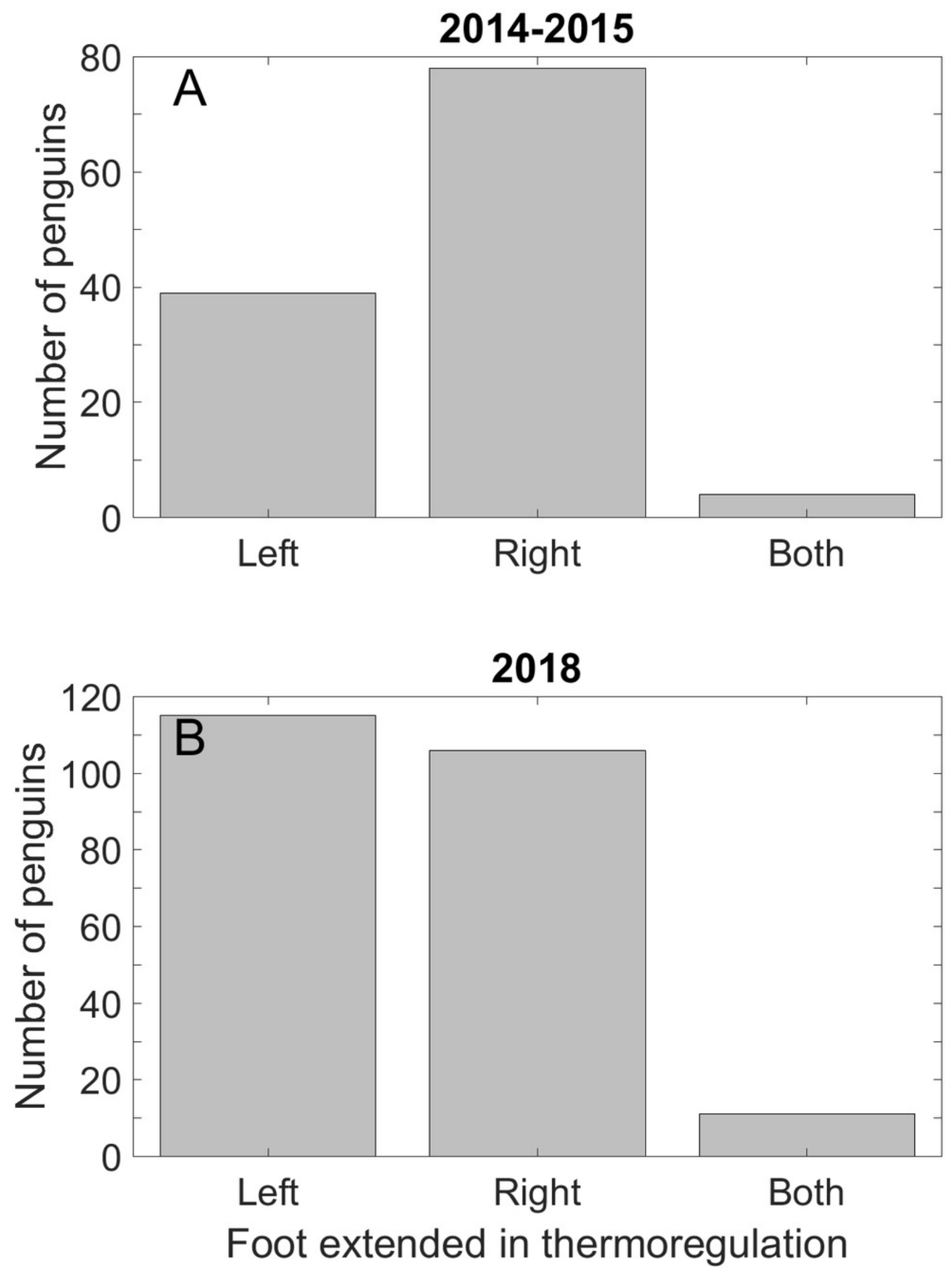


\section{Figure 7}

More than half of individual Magellanic penguins showed morphological evidence of a dominant flipper, but left and right dominants were equally likely in the sample.

We collected sterna from penguin carcasses at Punta Tombo and examined the keels for curvature. $29 \%$ curved to the penguin's left, $31.5 \%$ curved to the penguin's right, $6.5 \%$ had curves in both directions, and one-third had no curve $(n=76)$.

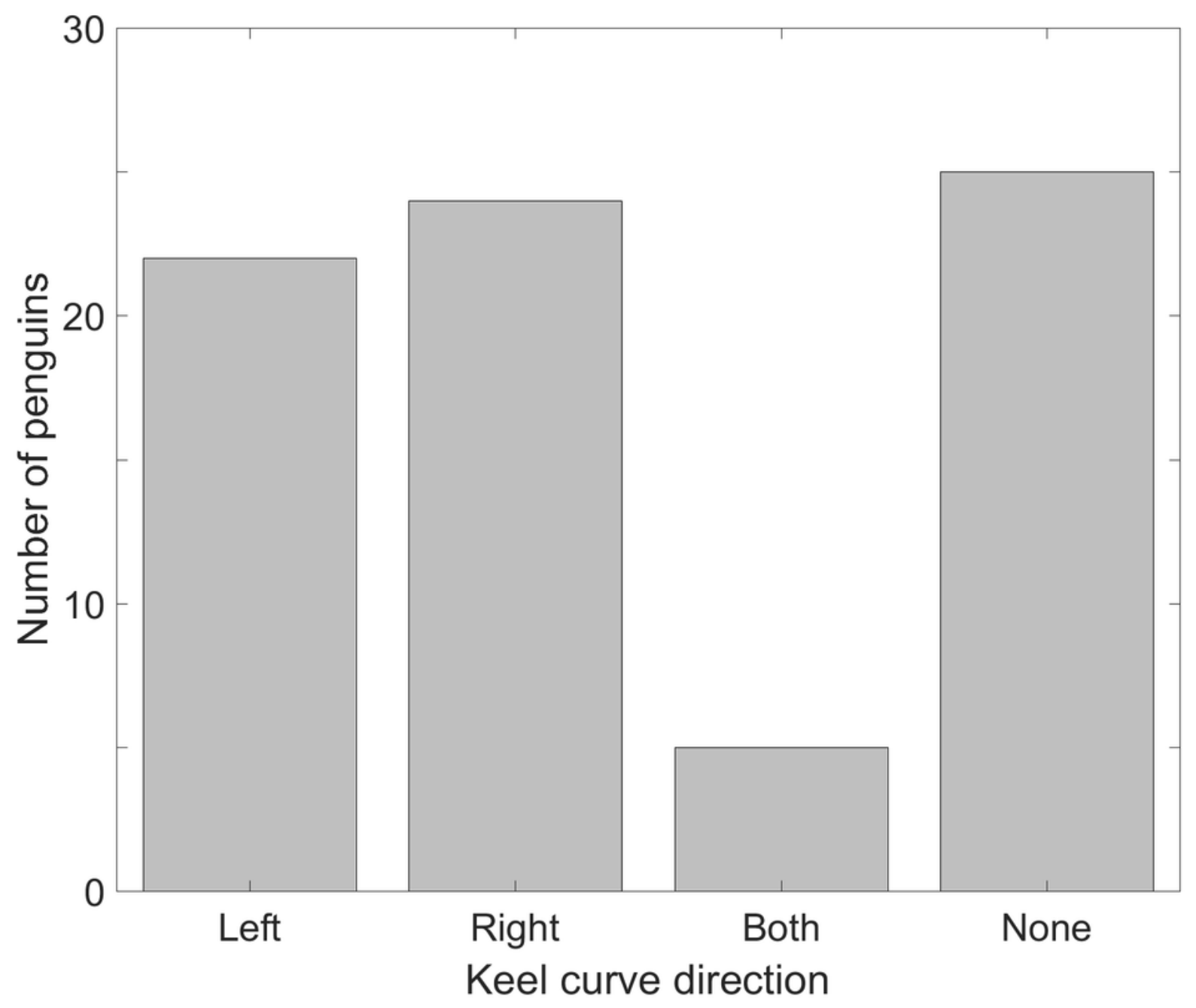




\section{Figure 8}

More female Magellanic penguins than males had feather wear on the trailing edge of the flippers, and more females $(n=74)$ than males $(43)$ had asymmetrical wear (more wear on one flipper than on the other).

A) More females than males showed feather wear on their flippers. Penguins replace their feathers annually, so noticeable feather wear is uncommon, especially in males. B) Of the penguins with some feather wear, right and left flippers were equally likely to have more wear (males: $p \sim 1.00$, females: $p=0.42$ ). 


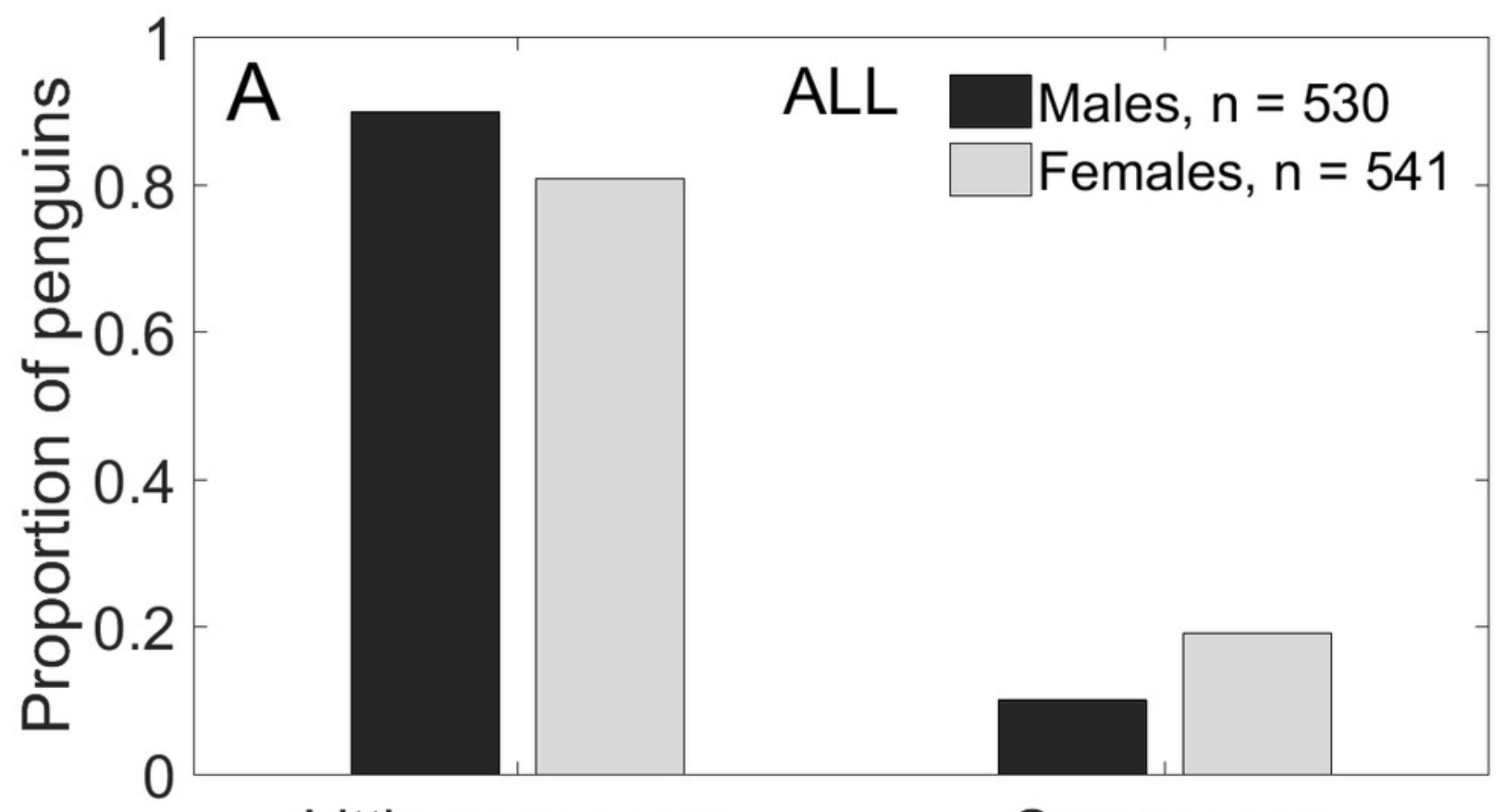

Little or no wear

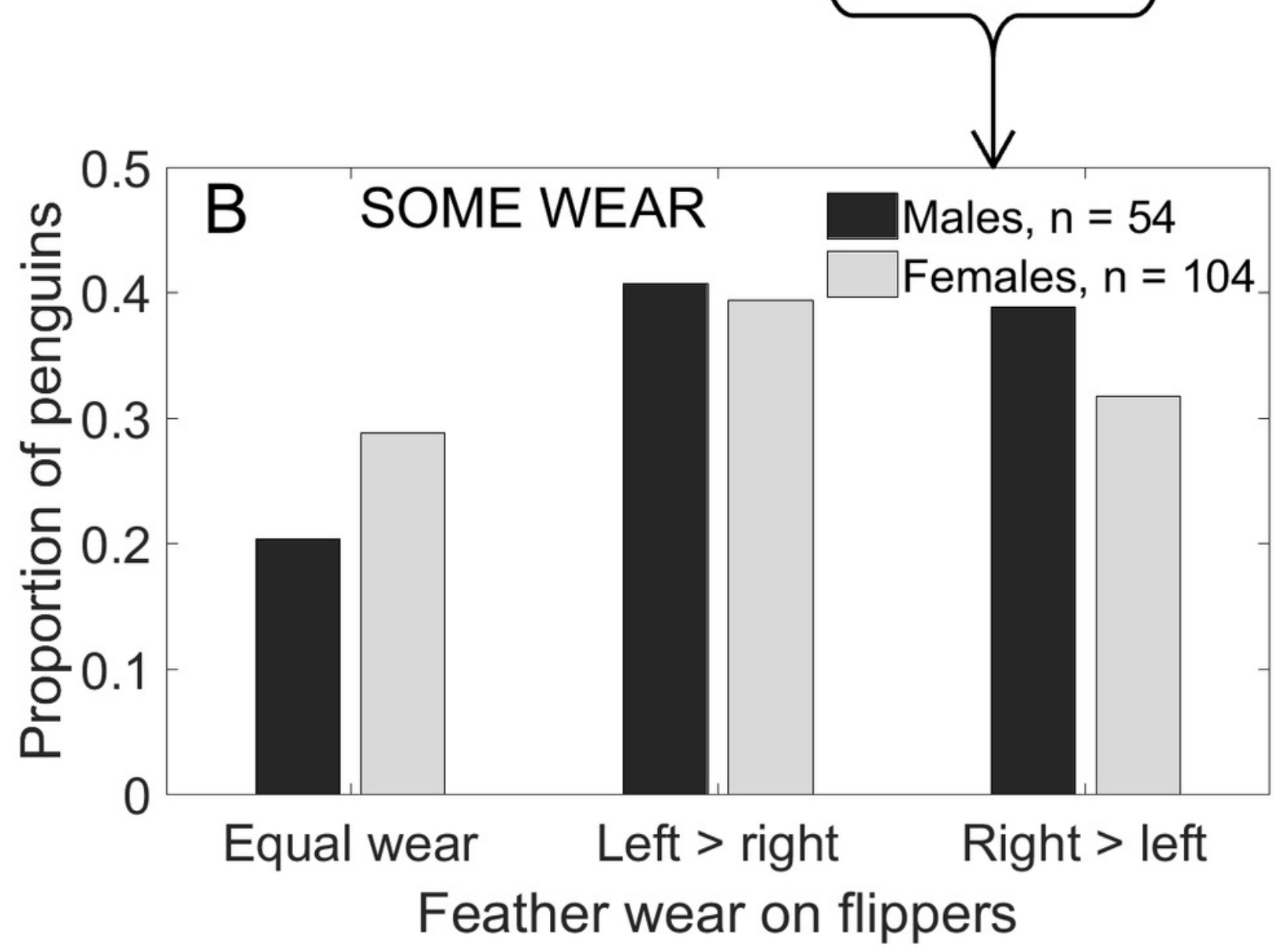




\section{Figure 9}

Magellanic penguins that had recently fought other penguins were more likely to have blood only on the right side of the face than only on the left side.

The tendency to have blood only on the right side or on both sides increased as the amount of blood increased. Penguins with blood covering less than $1 / 3$ of the face were scored as "little blood"; those with blood covering more than 2/3 of the face were scored as "a lot of blood".

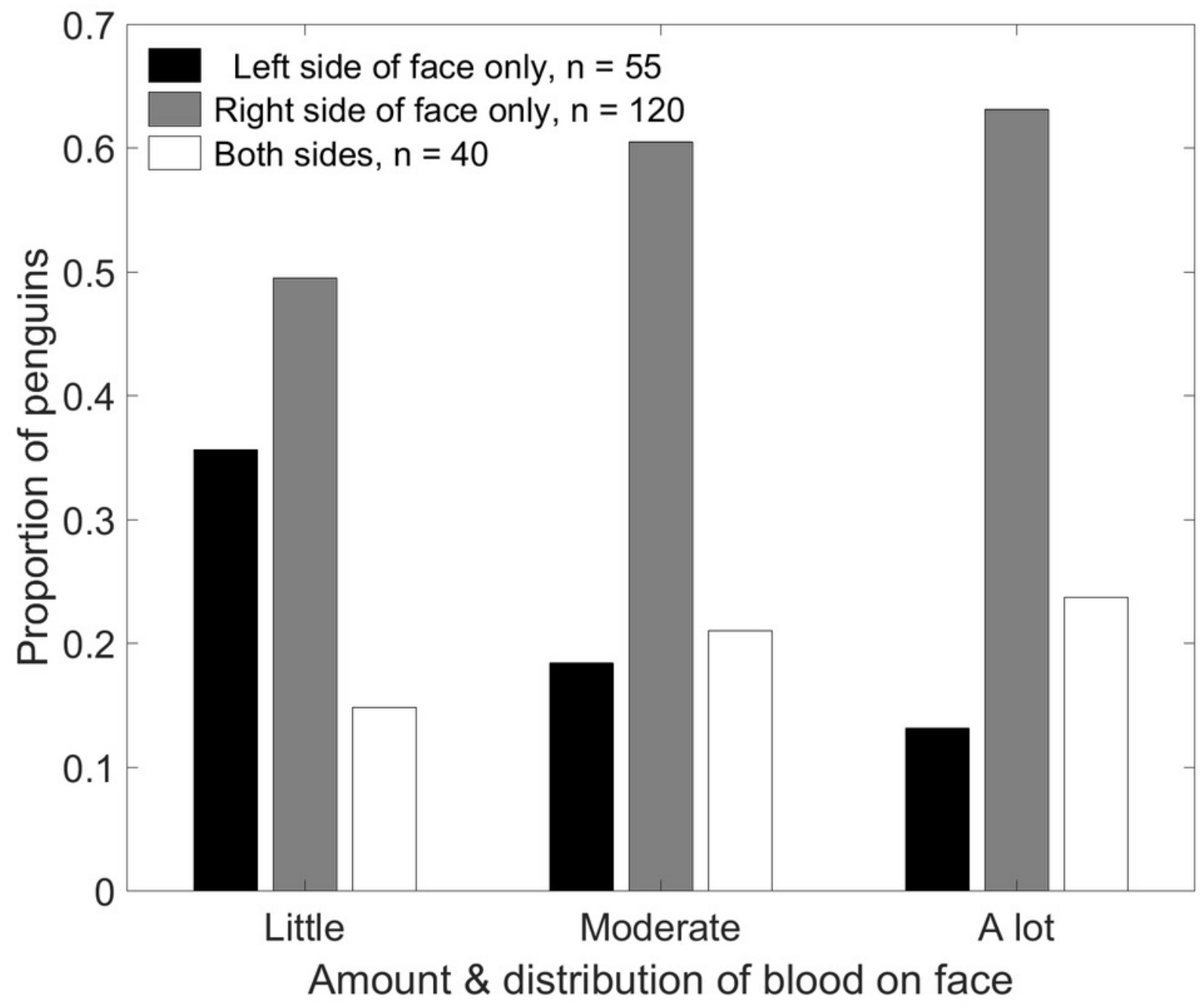


Figure 10

Fight orientations in Magellanic penguins.

There is a continuum from 1 to 4 . The bird labelled $A$ in each pair is the aggressor. The hatched area represents the blood resulting from cuts by the opponent's bill. In 2 through 4, the aggressor views his opponent primarily with his left eye; in 1, the birds view each other with their right eyes. In the course of a fight that lasts more than a few seconds, all these orientations could occur. Magellanic penguins had blood only on the right side twice as often as only on the left side, suggesting orientations 2 through 4 predominate.
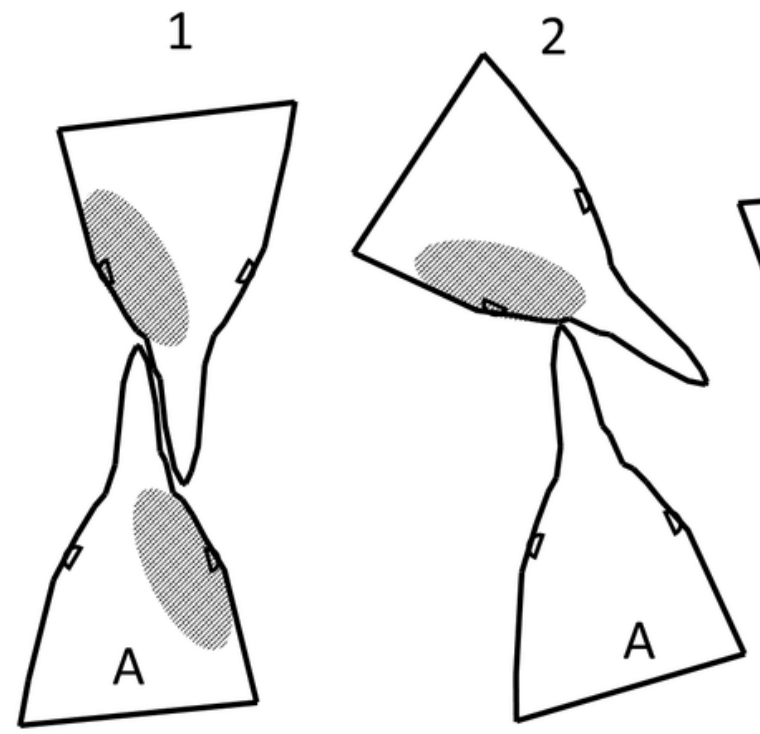

3

4
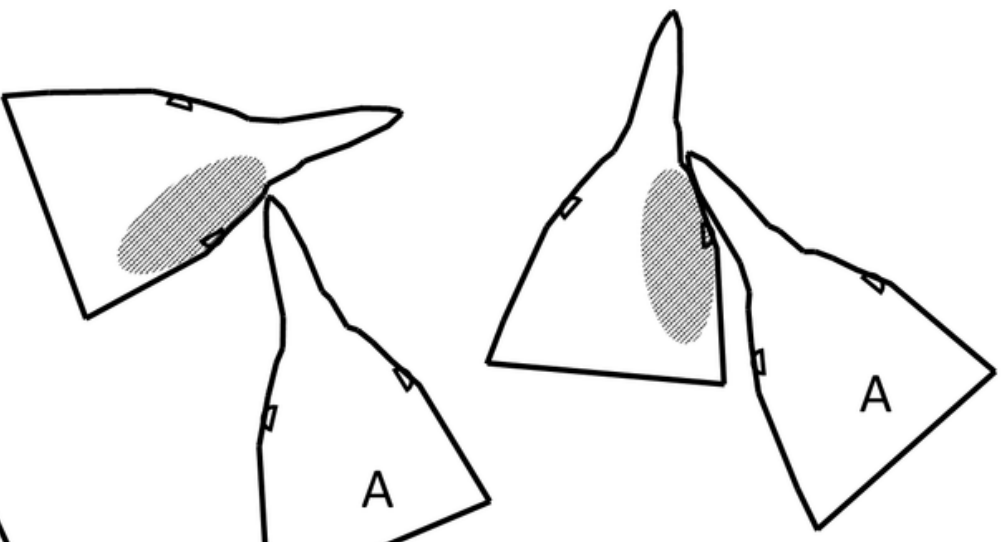


\section{Figure 11}

The curve in keels of Magellanic penguins' sterna overlaps the area of thinnest bone.

The curve strengthens the keel against the uneven pull of the muscles, and increases the surface area for muscle attachment. Photo credit: Ginger Rebstock

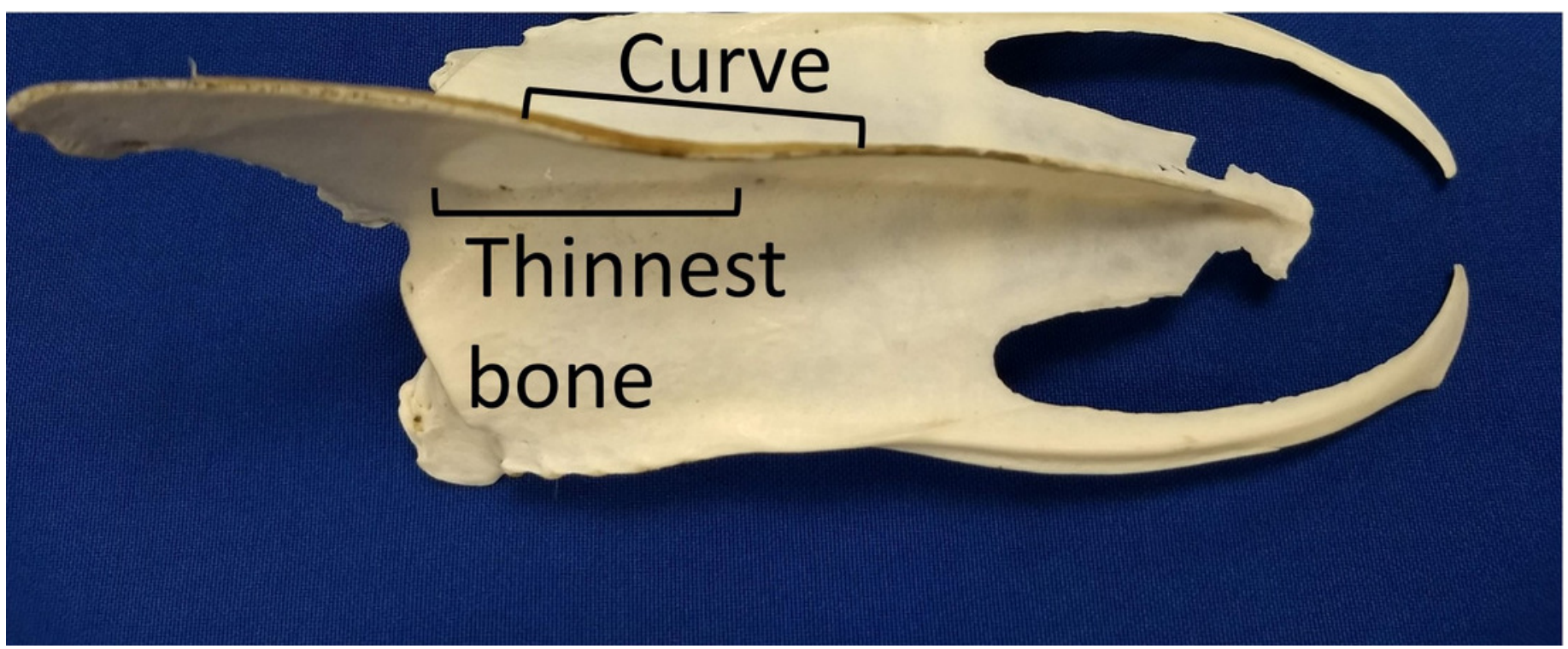




\section{Table $\mathbf{1}$ (on next page)}

Feather wear on the trailing edges of Magellanic penguins' flippers was uncommon and was equal on the right and left flippers more often than expected (diagonal elements).

Observed frequencies are listed first in each cell, followed by expected frequencies in parentheses. Observed frequencies that are greater than expected are in bold type; those that are less frequent than expected are italicized. 
1

\begin{tabular}{|c|c|c|c|c|}
\hline & & & Right flipper & \\
\hline & & Little or no wear & Moderate wear & Severe wear \\
\hline & Little or no wear & 1038 (980.7) & $47(77.0)$ & $5(32.2)$ \\
\hline Left flipper & Moderate wear & $48 \quad(70.2)$ & $22 \quad(5.5)$ & 8 (2.3) \\
\hline & Severe wear & 9 (44.1) & 17 (3.5) & 23 (1.4) \\
\hline
\end{tabular}

2 